TĖCHNICAL PROGRESS REPORT

$\cosh -2323-3$

on

Potential Well Formation in Electrostatic Confunement Devices

Prepared far

Atomic Energy Conmission

Division of

Controlled Thermonuclear Research

by

B. E. Cherrington, J. T. Verdeyen

Gaseous Electronics Laboratory

Department of Electrical Engineering

tniversity of Illinois at Urbana-Champatgn

tirbana, I11inois 61801

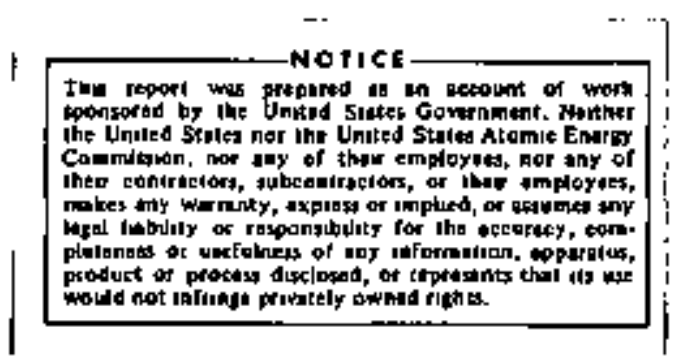




\section{DISCLAIMER}

This report was prepared as an account of work sponsored by an agency of the United States Government. Neither the United States Government nor any agency Thereot, nor any of their employees, makes any warranty, express or implied, or assumes any legal liability or responsibility for the accuracy, completeness, or usefulness of any information, apparatus, product, or process disclosed, or represents that its use would not infringe privately owned rights. Reference herein to any specific commercial product, process, or service by trade name, trademark, manufacturer, or otherwise does not necessarily constitute or imply its endorsement, recommendation, or favoring by the United States Government or any agency thereof. The views and opinions of authors expressed herein do not necessarlly state or reflect those of the United States Government or any agency thereof. 


\section{DISCLAIMER}

Portions of this document may be illegible in electronic image products. Images are produced from the best available original document. 


\begin{abstract}
The goal of this program is to evaluate the feasibility of using inertial electrostatic forces to confine energetic plasmas capable of sustaining fusion reactions. We have shown experimentally that electron injection lato a spherical system under high vacuum conditions produces a deep negative potential well. Our recent theoretical analysis of this system gives excellent agreenent with the experimental results. Of much more inportance is out observation of a stable multiple potential well structure (ion rich region In the center) when electrons are infected into a low pressure deuterium gas background. The extension of the theoretical analysis to explain these results do give qualtcative agreement with our experifmental results.
\end{abstract}


LEGAL NOTICE

"Th1s report was prepared as an account of Govermment-sponsored work. Neither the United States, nox the Atouic Energy Conmission, nor any person acting on behalf of the commission:

A. Makes an warrancy or representation, expressed or inplied, with respect to the accuracy, completeness, or usefulness of the information contained in this report, or that the use of any information, apparatus, method, or process disclosed in this report nay not infringe privately owned rights; or

B. Assumes any liabilities with respect to the use of, of for damages resulting from the use of, any information, apparatus, method, or process disclosed in this report.

As used in the above, 'person acting on behalf of the commission' includes any employee or contxactor of the Commission, ot employee of such contractor, to the extent that such euployee or contractor with the Commission, or employee of such contractor prepares, disgeminates, or provides access to, any information pursuant to his employment or contract with the commission, or his employment with such contractor." 


\section{A. Theoretical Studies}

Due to the sharply curtailed funding of this project, our most recent effects have concentrated on finding a theoretical basis for understanding our previous experimental observations. The extension of the Lavrentyev-Dolan analysis has allowed us to formulate a theory that successfully explains the potential well formation in spherical geometry when electrons are infected under high vacuum conditions. This anatysis ${ }^{1}$ gives excellent agreenent with our previous experimental results ${ }^{2}$. In particular, our analysis was performed for a Gaussian distribution in total and angular energies. This was one of the topics proposed in our contract renewal. A detailed stminary of our results, both experimental and theoretical, are contained in the two papers attached as appendices. 3,4 These papers were presented at the New York Academy of Sclences Conference on Electrostatic and Electrowagnetic Confinement of Plaswas and the Phenonenology of Relativistic Electron Beans, March 4-7, 1974.

In continuing our theoretical analysis, we have extended our work to the consideration of the double potential structure formed when electrons are injected into a low pressure deuterium gas background. In our initial analysis of potential well formation when electrons and ions are present ${ }^{4}$ we assumed narrow spreads in total and angular energies and we obtalned a multiple potential solution, although not a unique solution. Our latest studies using a narrow spread in electron energles and an angular spread in electron energies of about $5 \%$ (consistent with our experimental results) and using a narrow spread in ton angular energies but a broad spread in lon total energy (consistent 
wth a background Ionization source of ions) we found unique double potential well solutions which seem to be reasonably close to those suggested by the experfment. Dur present work involves more detalled study of these cases.

\section{Experimental Work}

The sharp curtailment of funds avallable for this profect virtually eliminated any posslbility of pursueing our planned experimental program. We had hoped to examine the potential wells formed when ion infection was used. Instead we pursued some small additional studies dealing with electron injection and which did not require additional funds for equipment as modification of our apparatus. We are presently undertaking minor refinements of the apparatus so that we can examine the dynanics of potential well formation and decay. This well give us sowe much needed insight into the fon production and loss mechanisus in our apparatus. 


\section{REFERENCES}

1. D. A. Swanson, B. E. Cherrington, J. T. Verdeyen, "Theory of the Negative Electrostatic Well in Spherical Geometry" to be published in Physics of Fluids.

2. D. A. Svanson, B. E. Cherrington, J. T. Verdeyen, "Potential Well Structure in an Inertial Electrostatic Plasma Confinement Device", Physics of Pluids, 16, $1939(1973)$.

3. J. T. Verdeyen, B. E. Cherrington, D. A. Swanson, and D. J. Meeker, "Recent Developments in Electrostatic Confinement-Experimental", presented at New York Academy of Sclences Conference on Electrostatic and Electromagnetic Confinement of Plasmas and the Phenomenology of Relacivistic Electron Beans, March 4-7, 1974. To be published In the Annals of the New York Academy of Science.

4. B. E. Cherrington, J. T. Verdeyen, D. A. Suanson, "Recent Developments in Electrostatic Confinement-Theoretica1". Presented at New York Academy of Sciences Conference on Electrostatic. and Electromagnetic Confinement of Plasmas and the Phenonenology of Relativistic Electron Beams, March $4-7$, 1974. To be published in the Annals of the New York Acadery of Science. 
FROFESSIONAL PERSONNEI

Name and Title

J. T. Verdeyen, Professor Co-Prinfcipal Investigator

B. E. Cherrington, Assoclate Professor Co-Principal Investigator

D. A. Swanson, Research Assistant

H. Honickman, Research Assistant
Percent of Salary Support Budgeted

0

(10z contributed by Untversity)
0

50

50 
Measurement of Electron Density in a Cylindrical Inertial Electrostatic Plasma Confinement Device

Multiple Potent1al WeIl Structure Created by Electron Injection In Spherical Geometry

Potential Well Structure in an Inertial Electrostatic Plasma Confinement Device

Theory of the Negative Electrostatic Well in Spherical Geometry

Recent Developments in Electrostatic ConfinementExperimental

Recent Developments in Electrostatic Conf inementTheoretical
D. J. Meeker

J. T. Verdeyen

B. E. Cherrington

D. A. Swanson

B. E. Cherrington

J. T. Verdeyen

D. A. Suanson

B. E. Cherrington

J, T. Verdeyen

D. A. Swanson

B. E. Cherrington

J. T. Verdeyen

J. T. Verdeyen

B. E. Cherrington

D. A. Swanson

D. 5 . Meeker

B. E. Cherrington

J. T. Verdeyen

D. A. Swanson
Journal of Applied Physics,

44, 5347 (1973)

0

Applied Physics Letter, 23, 125 (1973)

0

Ptysics Fluids,

16, 1939 (1973)

To be published in

Physics Fluids

To be published in Annals of New York Acadeny of Science

To be publtshed in Antals of Net York Academy of Science
100

50

100

100 


\title{
RECENT DEVELOPAENTS IN ELECTROSTATIC
}

CONFTHETENT - EXPERIIENTAL

J.T. Verdeyen, B.E. Cherrington, D.A. Swanson and D.J. Meeker

\author{
Gaseous Electronics Laboratory, \\ Department of Electrical Engineering, \\ Untverstty of Illinois at Urbana-Champaign, \\ Urbana, IL 61801
}

\section{Int roduction}

The motivation for this vork on electrostatic plasma confinament was provided by the experitnental results published by Hirsch. I. If order to put our work into proper perspective, let us review sone of the striking features of his work. The experimental aystem was based on the earlier ideas of Farnsworth ${ }^{2}$ and consisted of six energetic ion beams, arranged symutrically around a grounded permeable sphere and focussed to converge at the center. When the Ion besms were accelerated through potentials of 50 to $150 \mathrm{kV}$, coptous quantities of neutrons $\left(10^{6}-5 \times 10^{9} / \mathrm{sec}\right)$ were emitted from the device and the neutron emission depended inversely on the pressure of the deuterfum or D-T mixtures utflized ( 0.1 to 8 microns). Some of the ware prosaic explanations for the neutron production can be dismissed on the basis of the experiments. The fact that the neutront production increased with decreasing pressure ellioinates the beamgas Interaction theory. The decrease in performance when the beauls vere purposely nisaligned russ couter to the suggestions that the origin of neutrons arght be a bean-solld target effect. Varlous experi- . ments wers performed to ascertain the origin of these neutrons, fn

$*$ Th1s work was supported by the U.S. Atonflc Energy Conalssion under Contract At(11-1) - 2323. 
particular to see if they resulted from fusion in the center of the device and led to the formation of a simple model for the device's operation.

Th1s model was based on the solution to Poisson's equation for the bipolar diode with ions being created at the grounded anode and accelerated through permeable, electron endting cathode held at a negative potential. Solutions to this equation fox wonoenergetic particles with perfect radial aiming, leads to the prediction of altemating layers of positive and negative space charge with large electrostatic pressure appearing in the center of the device. Such regtons could confine the energetic Ions for sufficient time for fusion reactions to take place as was observed experimentally.

In spite of the severity of the assumption of perfect radial focussing and mononergetic particles, this'model predicted many features which were consistent with the observation in these early experiments. For instance, multiple peaks of gamma emission were observed frow the device suggestive of brenmstrahlung being enitted by electrons passing through the multiple virtual, anodes.

Our experiments at the University of Illinois have been designed to examine the potential structure and charge densities within the interior of a simflar device so as to ascertain whether such alternating layers of space charge can exist. In spite of the obvious limitation of the simple model proposed by Hirsch, it 
appears to explain many of the features found in his experiments, and serves as a useful guide for ours. Deep potential wells (i.e., 20 to $80 \%$ of the applied potential) have been measured with single opecies (electron) injection, with aultiple wells being formed in the presence of background gas. Furthenore, the background plasta density shows an oscillatory behavior in space. Both results are suggested by the simple theory and partially confirmed by the more exact (but compiex) theories of Larentyev, ${ }^{3}$ Dolan, ${ }^{4}$ and Swanson, 5,6 and Ine1. 7 The following sections will describe the methods we have uged to analyze such plasmas in an electrostatic environment.

Athough this version of electrostatic confinement was advanced with the goal of a fusion reactor, ${ }^{2}$ - and it might achleve that afm - the results showing the existence of stable potential vells capable of trapping particles of oppoaite charge are applicable to other fusion schemes.

\section{Electron-Beam Probing of Potential Wells}

A. Electron injection into a hard Vacumn.

The apparatus used to study the potentfal wells that might be formed in an electrostatic containment device is shown in Fig. 1. Electrons are injected inco the interior of the device through the olot In the grounded spherical shell by pulsing the hot cathode negative by 100-300 volts. These electrons are attracted by a highly 
transpatent ( $93 \%$ open) anode held at a posttive potential. Even though the inttial source of electrons is decidediy non-miform, expertmental evidence - to be discussed later - allows one to conElder the injection to be spherically symmetric.

in electron beam from an osctiloscope gur is used to - probe the 1nterfor of the device. Sinusoidal voltages are applied to the deflection plates leading to a clrcular Lissajous pattem on the screen on the far side. The amplitude of these, voltages controls the apex angle of the cone swept out by the probing beam.

Obviously, the attractive positive potential of the anode alone w11 tend to contract the circle, whereas any negative charge on the Interior of this cone will scatter or expand the circle. Finally, If there were to be both positive and negative space charge layers as suggested by Hirsch's early model, the change In trajectory will depend upon the net charge contained within the cone of the probing beam.

The energy of the probing beam and the deflection plate voltages are independent parameters of the experiment. By varying these quantities, one can test the consistency of an assutred potential varlation on the interior of the device. Although it is always possible to plck a potentisi function to e:plain scatteriag data at one energy, a close approxidation to the true function is necessary to watch data for a 50:1 variation on the beam parameter.

This procedure is easter and in some cases more accurate than attempting an Inverston technique similar to the Abel ${ }^{B}$ process. 
We have, therefore, used the beam probing data to check the conadstency of our assumed potentials.

The success of this approach is illustrated in Fig. 2 where the focussing properties of the anode alone are presented. The photographic insert indicates how the graphical data was taken.

- One compares the dianeter of the Lissajous "circle" for various values of the ratio $v_{A} / V_{G}$ leading to the graph shown. Inctdentally, this comparison, $\mathrm{D}\left(\mathrm{V}_{\mathrm{A}} / \mathrm{V}_{\mathrm{G}}\right) / \mathrm{D}(0)$, is Independent of deflection plate voltages (i.e., the initial diameter) and is a unique function of the ratio $V_{A} / V_{G^{*}}$ Consequently the probing bean can be treated as a "paraxial ray" obeying the linear differential equation:"

$$
\frac{d^{2} r}{d z^{2}}+\frac{v_{0}{ }^{-}(z)}{2 v_{0}(z)} \frac{d r}{d z}+\frac{v_{0}(z)}{4 v_{0}(z)} r=0
$$

where $v_{0}(z)$ is the potential variation along the axis of the probing beam with the primes indicating the derivative with respect to $\mathrm{Z}$, and $r$ is the distance froth the axis. Equation 1 , of course, is exactly equivalent to the equations of motion tn a cylindrically symmetric system provided $(\mathrm{dr} / \mathrm{dz})^{2}$ is small compared to 1 .

The fact that the equation is linear and of second order allows us to tse the matrix forulation in our data interpretation that has proved so successful with optical beams. 10 


$$
\left[\begin{array}{l}
r_{\text {out }} \\
r_{\text {out }}^{\prime}
\end{array}\right]=\left[\begin{array}{ll}
A & B \\
C & D
\end{array}\right]\left[\begin{array}{l}
r_{\text {INITIAL }} \\
r_{\text {intitial }}^{\prime}
\end{array}\right]
$$

with the inftial posttion being zero and the initial slope given by $D(0) / 2$ divided by the distance from the gun to screen.

of course the $v_{0}$ in Eq. (1) is for zero space charge. When the electrons are infected into the device, this condition is not true. However, if one assumes that the potential function in the presence of space charge can be expressed as a two-term Taylor series, va.

$$
v_{(x, z)}=v_{0}(z)+\frac{x^{2}}{a^{2}} v_{2}
$$

then Eq. (1) becomes for a paraxial electron;

$$
\frac{\partial^{2} r}{\partial z^{2}}+\frac{v_{0}^{\prime}(z)}{2 v_{0}(z)} \frac{\partial r}{d z}-\frac{v_{2}(z)}{2 a^{2} v_{0}} r=0
$$

Agaln, we have a linear second order differential equation permitting the matrix fortulation of Eq. (2).

The Inearity Implied by Eq. (4) is observed with electron Infection Into the central region. One Intuitfvely expects, and one 
observes the probing beam being scattered by the accumulated charge. But, again, the ratio $D\left(V_{A} / V_{G}\right) / D(0)$ is independent of $D(0)$ and is a function of the ratio of $\mathrm{V}_{\mathrm{A}} / \mathrm{v}_{\mathrm{G}}$ and the injected current.

Experimental data fllustrating the scattering by the accurulated space charge are shown in Fig. 3. Again, we plot the diameter of the screen pattern normalized to the fnttial diameter (i.e., with $v_{a}=I_{a}=0$ ) as a function of the focussing parameter $v_{A} / v_{G}$ for a constant ctrrent of 60 mA. Figure 3 also shows the theoretical ratio if one uses the Langmuir model ${ }^{11}$ of injected electrons with perfect radial focussing with zero angular monentum. Obviously, the experfmental data deviates conslderably from Languir's prediction. The fact that the nomalized deflection is independent of the initial trajectory of the probing beam - over the range of experimental parameters available to us - shows that, the probing ray obeys a linear differential equation such as Eq. (4). If one assumes apherical symetry (and Fig. 5 verifies this), then it is reasonable to use a parabolic potential well as a model for the analysis fin the Intertor of the anode. The depth of the parabolic well is charactertzed by the paraneter, $f$, ss being a fraction of anode voltage (1.e., the well is $f \cdot v_{a}$ deep).

The theoretical predictions based on this model agree reasonably well with experimental data as shewn by the dashed curves of F1g. 3. The more exact calculations, to be discussed in the followIng paper, fustffy this assumption and show that it is a consequence of the angular momentum of the injected electrons. 
From data such as this, one can estimate the functional dependence of the well depth on anode voltage and injected current. For Instance, the fraction $f=0.64$ agrees reasonably well with the experimental points for $v_{a}=500$ volts. Thus, the absolute depth is $0.64 \times 500$ or 320 volts. Sialilarly, the case of $v_{a}=1000$ volts Indicates $f=0.36$ or a depth of 360 volts. The close coincidence of these two values suggests that the well depth is only a function of the injected current and is rather insensitive to anode voltage. Th1s is shown in Fig. 4 which was constructed from graphs of data such as Fig. 3. The variation of well depth with infected current is also indicated here. The more exact theoretical model Justifies the nearly linear dependence of well depth on current for low values of $f$.

\section{B. Bipolar injection}

The Ideal test of the simple motel of electrostatic confinement would utilize ion and electron injection. Unfortunately, this is not easily achleved in an experiment, and we have relied on background tonization of gas atons by the enfected electrons to provide fons in the system. Whereas the system was continuously pumped for the experiments in IIA, ( $p=2 \times 10^{-8}$ TORR), here a swall gmount of deuterium is admitted to the chamber of Fig. 1. The pressure was not allowed to rise to values at which it affected the optics of probing beams, however. 


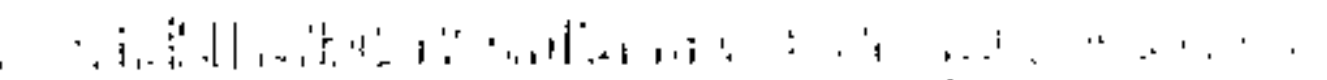

b. -

F1gure 5 sthots photegraphs of the effect that one observes as the pressure is increased. Hete, we show 8 arcs of a circle corresponding to the times at which the probing gun is unblanked during one revolution (counter-clockwise) of the circular Lissajou pattem (16.6 msec). During each time the gun 1s unblanked, electrons are infected for 300 usec. Thus, the Initial and final portions of the arcs represeat the beam position with no injected current, and the central portion is that with injected current. Other experiments have demonstrated that this effect is a steady state phenomena, the use of pulsed operation ts torely to prevent electrode heating and destruction.

Not1ce that in the hard vacuun case, Fig. 5(a), the probing beam is scattered In the manner discussed previously. As the pressure is increased as in FIg. 5(b), the beam appears to "sag" back toward its initial trajectory - almost as if the Ions are neutralizing the negative space charge. If this were true intfornly wthin the incerior of the anode, the beam should retum to its Initial position with $I=0$.

But, F1g. 5(c) shows that the beam is attracted cowaxd the 'oxis for the higher pressure case (1.e., higher ton generation rate). This experiment strongly suggests a region of postclive space charge within the negat 1 ve well created by the electrons.

There are two posstble space charge distributions whtch woutd explain Fig. 5; a weak postefvely charged interior, (of the anode) 
corresponding to a high loss zate of the electrons from plasma tnterfor, or a shell structure (like an onion) with the net positive charged inner region trapped by the surrounding negative space charge.

Figure 6 demonstrates that the 1atter ylewpoint is the correct one, Here, the cone angle of the probing beam is varied. When the bean trajectory passes close to the center, F1g. 6(a), 12 Is at tracted towards the axis; when it misses the central region, Fig. $6(c)$, it sees only a net negative space charge. This physical interpretation is strikingly similar to the predfctions of Hirsch's model.

Although the existence of the double well is clearly established, the analysis of this case is not nearly as advanced as it is on the negative well of Section IIA. This is due to the fact that experimental uncertaintles about the shape of the negative well compound the difficulty, making data reduction extremely tedious and prone to error. Nevertheless, one can make reasonable asstmptions, coupled with experimental data to obtain approximate values of the positive charge density.

The negative well formed in the hard vacuun case, shown In Fig. 5, corresponded to a 307 depression in the potential within the anode with 20 mA injected current. Since the anode voltage vas 2500 volts, the absolute well depth $15750 \mathrm{~V}$ and the naked electron density is $1.6 \times 10^{8} \mathrm{~cm}^{-3}$. The positive 1on density in the high pressure case must exceed this value over a linfted range of the central region. 
If we assume that the net positive charge is also uniform over a linited region, say $x<R_{1}$, one can attempt to match the theoretical prediction of the deflection for various values of $R_{I}$ to the experiment. This procedure allowed us to estimate $R_{1}$ to be $21.0 \mathrm{cr}$ (compared to $3.2 \mathrm{cra}$ radius for the anode). Thus the local tow density would be $3.2 \times 10^{8} \mathrm{cr}^{-3}$ for $\mathrm{r}<1 \mathrm{~cm}$ wth a potential rise from the edge of the well of 49.6 volts or a rise of 125 volts from the botcon of the well.

At first glance, there is an inconsistency in this calculation - the center is some 625 volts below the anode potential and the ions could never escape over the potential barrier. If one assumes that the dominant 100 is $\mathrm{D}_{2}^{+}$and uses a resonant charge transfer cross-section of $10^{-14}$ to $10^{-15} \mathrm{~cm}^{2}$, and picks an average energy of the trapped fons to be 13 volts (consistent with the Inferred potential distribution), then the fon lifertme is 14 to 140 usec. for the pressure used here $\left(8 \times 10^{-5}\right.$ TORR). Considering the spproximations involved, this is amazingly close to the time neasured by Swanson 12 for the formulation of equilibrium situation. Hence we conclude that the picture of a stable, positively charged, Interior is consistent with known rate processes.

III. Measurement of the Charge Density Distribution Although the electron bean measurements have established that stable, rultiple potential wells can exist, one can only infer 
the difference between the ton and electron densfties from the potential variation. In order to obtain these destred quantities directly, a cylindrical system was utllized in conjunction with a microwave Fabty-Perot ${ }^{13,14}$ cavity (at 35 and 70 Giz) or a laser heterodyne system operating at $3.39 \mu$. The cylindrical system is convenient for these types of measurements since both depend upon the Integrated density along the axis of measurement. If end effects are ignored, the cylindrical system affords the most straightforward Interpretation of data.

An end view of the 16 on long gystem used 18 shown in Fig. 7. This system can be used with electron or fon injection into the central region; only the latter is discussed here. The electrons emitced by the hot cathode are attracted by the accelerating grid and repelled by the center electrode held at a constant negatfve potential. The fons formed in the space between the grids are then at tracted towards the central region through the highly transparent ( $92 \%$ open) electrode.

Figure 8 shows the electron denstty as measured with a atcrowave Fabry-Perot cavity in the central region as a function of the injected fon current with the center electrode voltage held conotant. These measurements are a spatial average with the local denstty weighted by the square of the migrowave fleld. ${ }^{16}$ In other words, no attempt is made at this point to Infer spatial structure to the density.

It is important to recognize that, the electron density If the measured quantity even though lons are the injected particles. 
Consequently the non-linear increase of equilibrium electron density wth injected Ion current shown in Fig. 7 is a gtrong indication of trapping of the electrons formed in the central region by the Iontc space charge, similar to the reverse situation discussed earlier in section $\dot{1} I B$.

Spatially resolved measurements of the electron density taken with the Iaser heterodyne systers are shown in Fig. 9. Duk to the very small size of the laser bean ( $(1$ mm diameter), the averaging process is only applicable for the axtal coordinate. Even though there is a small amount of dissymetry to the measurements, most of the spatial variations are far in excess of the errors involved, Consequently, this definftely shows a spatially oscillatory form of the plasma - again similar to that. suggested by Hirsch's simple model.

It should be clear, however, that these densityes are assoctated with an Inhowogeneous plasma and are not the "naked" charge densities. A simple application of Gauss' Law indicates that the uncovered charge density can be at most $5 \times 10^{8} \mathrm{~cm}^{-3}$ for the potentials used here. Since the densities are on the order of $10^{11}$ to $10^{12} \mathrm{~cm}^{-3}$, this must represent the nearly conpensated charge density of the background plasta.

\&

IV. Sulmaxy and Conclusions

There is not a couplete one-to-one correspondence between chls work and the earlier expertments. Hirsch used guns for the fon 


\section{.}

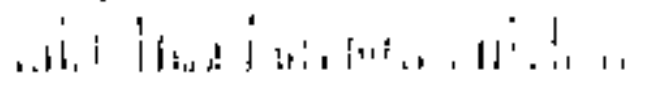

A' L I:

scurce and depended upon electrons emitted by lon bombardient of the center electrode for the negative charge. This is an excellent (but difficult) approximation to the stmple model since the charged particles ortginste at a well defined location.

In the experiments described here, the use of gas ionfzation to generate the ions makes the identification of the energy and angular monentum of the particle diffictlit. of course, the potentials used here are ordexs of magnitude lower than those used by Hirsch. Nevertheless, many of the ideas guggested in this early work are observed in these experiments.

Alhough electrostatic confinement was inftiated as alternative to magretic confinement for fustan purposes, it should be clear that any system permitting the escape (or injection) of a single type of charged spectes will have the space chaxge flelds and resultIng Influence on the plasma as have been observed here.

It is not possible to estimate the viability of this approach to fuston without some assumtion of a model. Hirsch did this using the general 1deas of the simple monenergetic model and concluded that one could conceive of small power reactior th the intemal circulating current between virtual electrodes was much laxger ( $210^{4}$ ) than the external current. Elmore, Tuck, and Wats $n^{17}$ exantned the case of $a$ central core of fons confined by the injection of an electron current. They concluded that it would require excessive extemal power input and would probably be unstable. They did not, however, allow for the multiple vell structure as has been observed here. 
Although $r-f$ oscillations (In the 10 to 500 MHz range) appear on the anode in our experiments with electron injection, the presence (or absence) does not affect the gross behavior of the central tegion. Indeed, it appears as if those oscillations are trans1t time 18,19 phenomena of electrons interacting with the anode arcult.

To extrapolate these experimental results to reglons of fusion interest requires considerable faith in the siope of data taken as 1-3 kV remaining constant to $300 \mathrm{kV}$ : Obviously, more data 10 needed. 


\section{References}

1. H1rsch, R.L., J, Appl. Phys. 38, 4522,(1967), See also Phys, Flutds 11, 2486 (1969).

2. Farnsworth, P.T: , J. S. Patent No. 3,258,402 Issued June 28, 1966.

3. Levrentyev, O.A., Magnitnye Lovushki Vypusk 3 (Nankova Dunka, Rlev, U.S.S.R. 1968) q. 77-147 [AEC report No. AEC-tr-7002, 2970].

4. Dolan, T.J., J.T. Verdeyen, B.E. Cherrington, and D.J. Meeker, J. App1. Phys. 43, 1950 (1972).

5. Swanson, D.A., B.E. Cherrington, J.T. Verdeyen, Phys. Fluids. (To be pubitshed).

6. Swanson, D.A., B.E. Cherringt on, J.T. Verdeyen, Appl. Phys. Let. 23, 301,(1973).

7. Imel, G., M.S. Thesis, Pennsylvania State University, (1973).

8. Bockasten, K., J. Opt. Soclety 5l, 943, (1961). (See Also W.M. Black, Ph.D. thesis, Department of Electrical Engtneering, Pennsylvania State University, (1971).

9. Spangenberg, K., "Vacuum Tubes," HcGriw-Hil1, p. 350. Wew York, New York, (1948).

10. Kogelnik, H., and T. L1, Appl, OptLes 5, 1550, (1966).

11. Langou1r, I., and K.R. Blodgett, Phys, Rev. 24, 49, (1924).

12. Swanson, D.A., B.E. Cherringt on, J.T. Verdeyen, Phys. Flu1ds 16 , $1939,(1973)$ 


\section{Reference - 2 -}

13. Heeker, D.J., J.T. Verdeyen, B.E. Cherr1ngton, J. App1. Phys. 44, 5347, (1973) .

14. Chaffin, R.J, and I.B. Beyex, IEEE Trans. Microwave Theory Tech, Irx-16, 37, (1968).

15. Liu, C.S., J.T. Verdeyen, B.E. Cherrington, J. Appl. Phys, 40, 201. (1969).

16. Brown, S.C., "Basic Data of Plasma Physics." (Wiley, New York, 1959), Chaps. I and 4 .

17. Elmore, W.C., J.L. Tuck, and K.M. Watson, Phys. Fluids $\underline{2}, 239$, (1959).

18. H1rsch, R.L., Phys, Flu1ds 11, 2486, (19,69).

19. Klevans, E., (Private Commonication). 
Fig. 1. Schenatic d1agram of the spherical device used for electron bean probfing. The radius of the fnner transparent anode is $3.18 \mathrm{~cm} . ;$ the radtus of the grounded sphere $1510 \mathrm{~cm}$.

Fig. 2. Electrostatic focussing properties of the anode. The photographic insert illustrates the method of taking the data present in the graph. The ellipticity show here is due to the mequal distances from the hortzontal and vertical deflection plates to the anode.

F1g. 3. Norwalized experimental and theoretical deflections vs. normalized anode voltage for a constant injected current.

F18. 4. Absolute vell depths $\left(f \times \nabla_{A}\right)$ under the condtions of constant current and constant voltage.

F1g. 5. A photograph of the deflection pattems seen at various background pressures.

Fig. 6. Change in the deflection pattem as the initial slope of the probing beam is changed. The arc marked $B$ corresponds to the deflection when the current is injected for 300 wsec.

P1g. 7. End view of the cylindrical device, the length of the outer.cylinder is $20 \mathrm{~cm}$, with a $16 \mathrm{~cm}$ Inner electrode.

Fig. 8. Electron density in the cylindricsl device as measured with the microwave Fabry-Perot cavịty.

F1g. 9. Spatially resolved electron denstity on the interior of the cylindrical device as determined with a laser heterodyne eystem. 


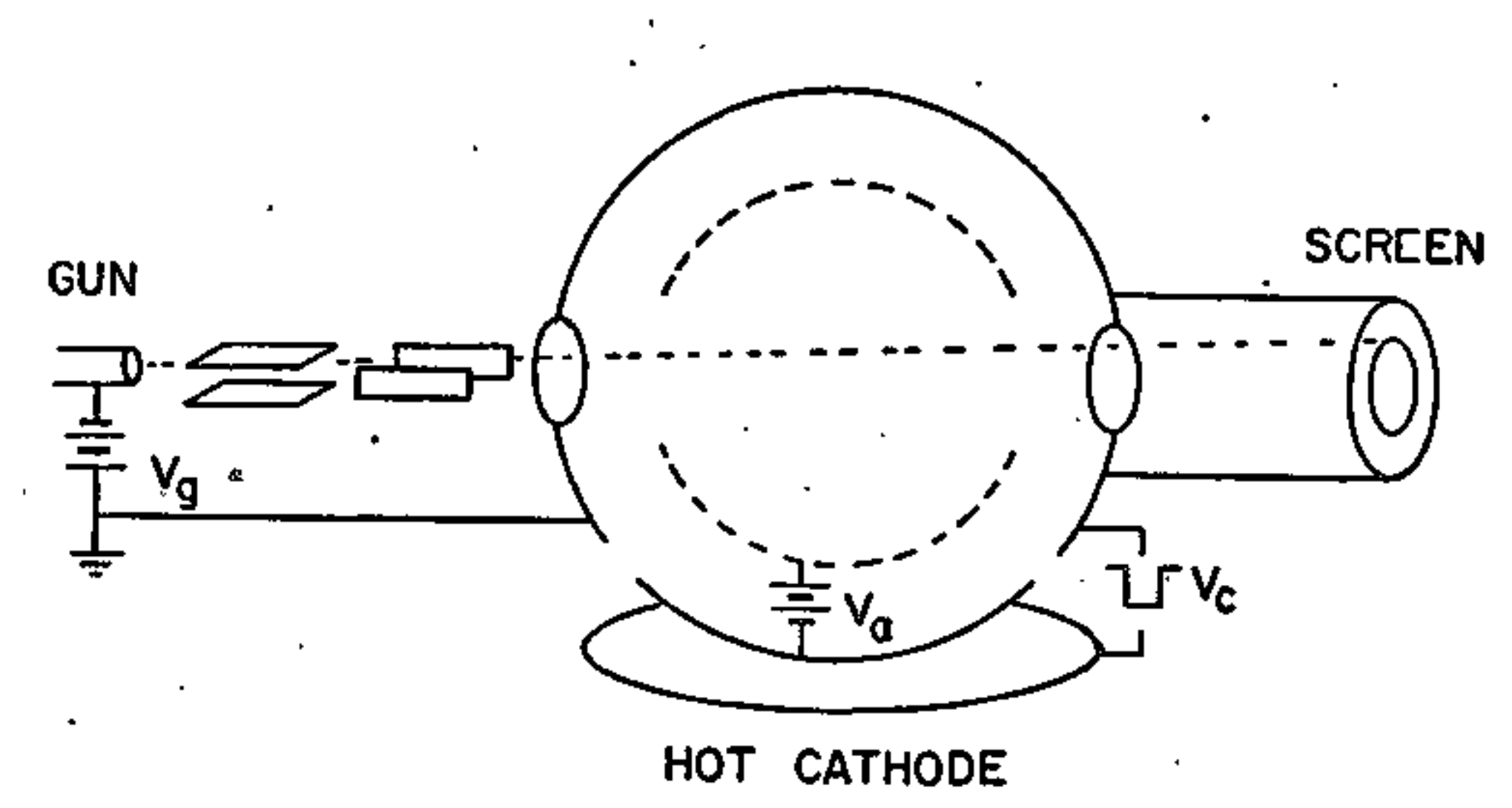




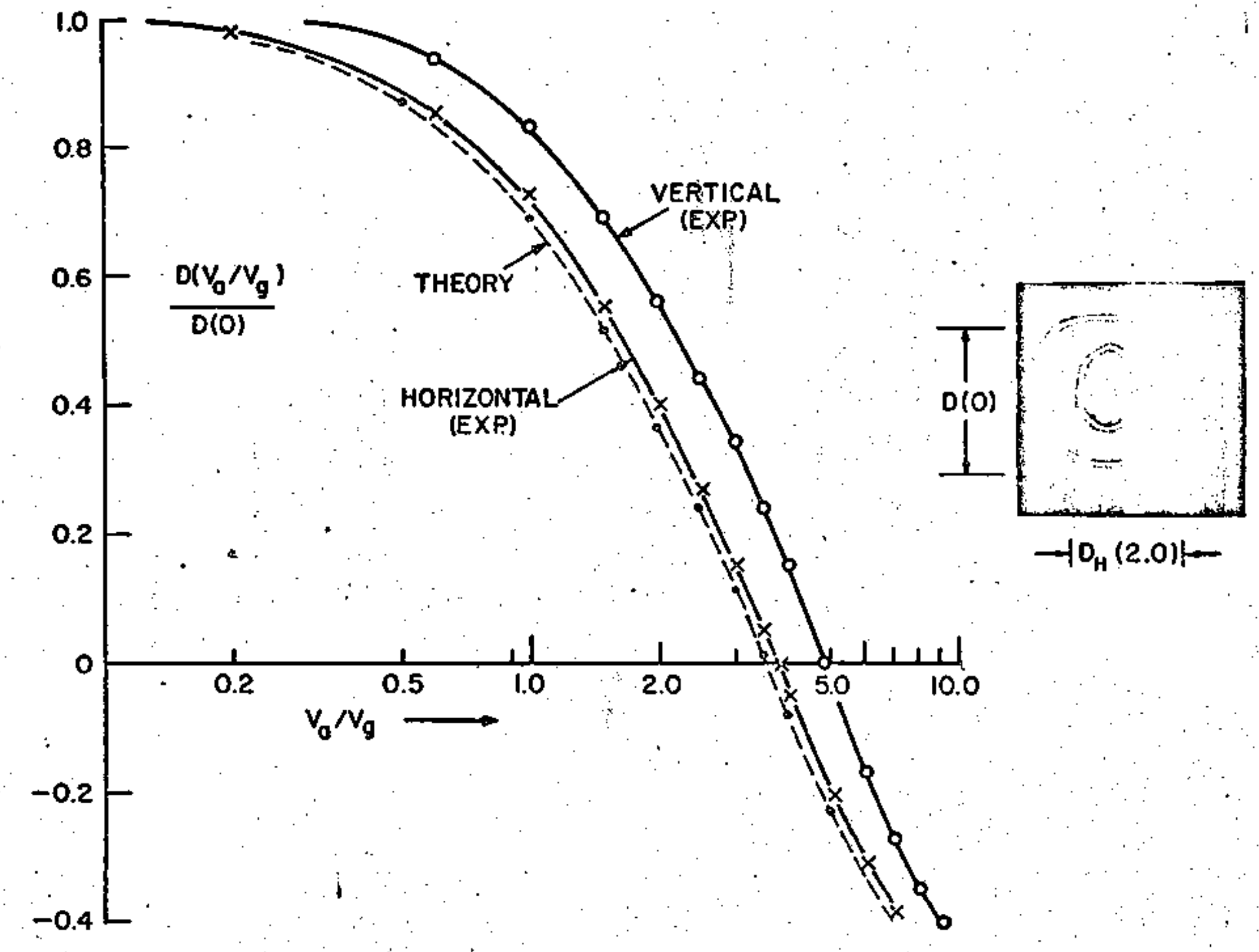




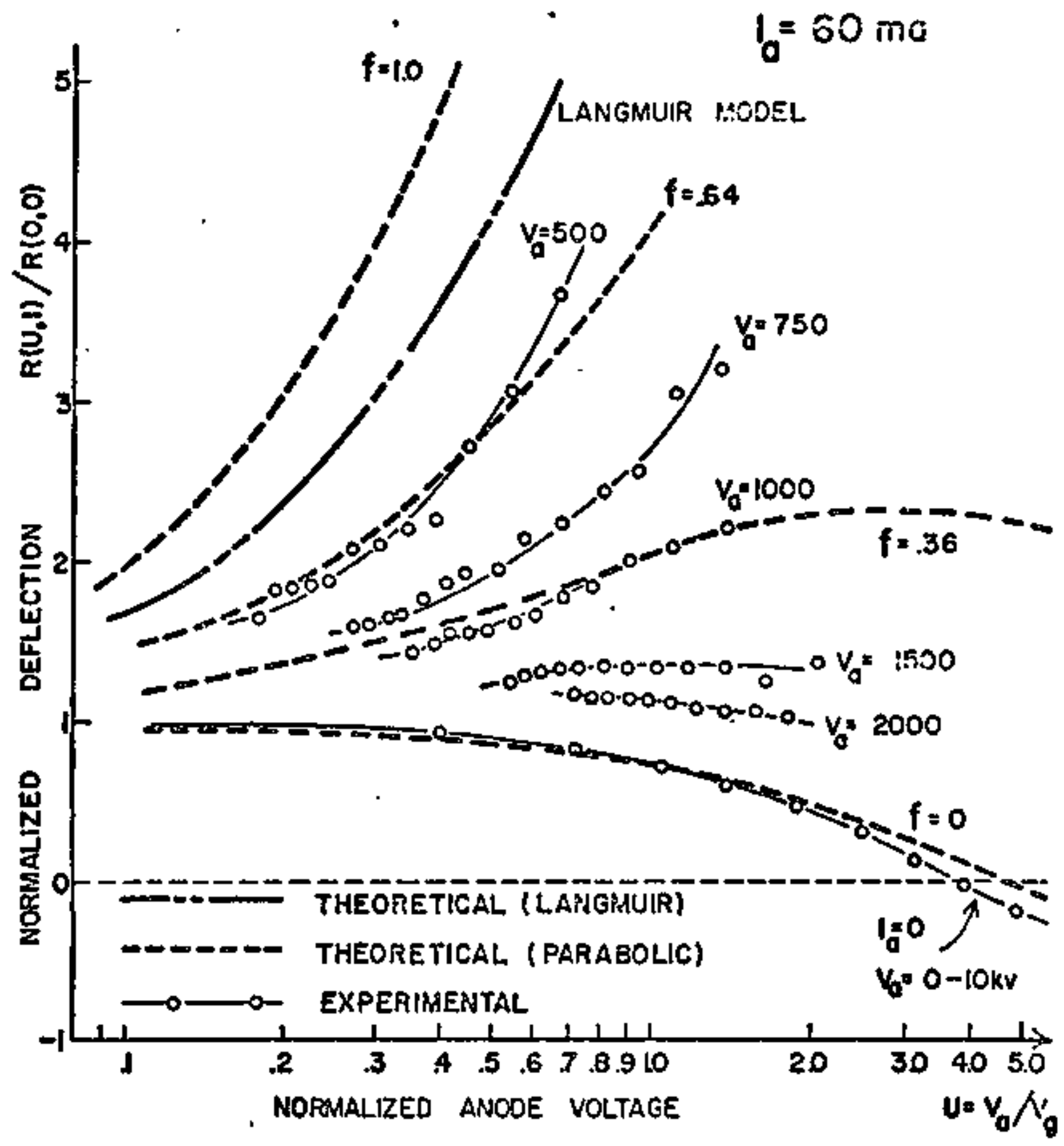



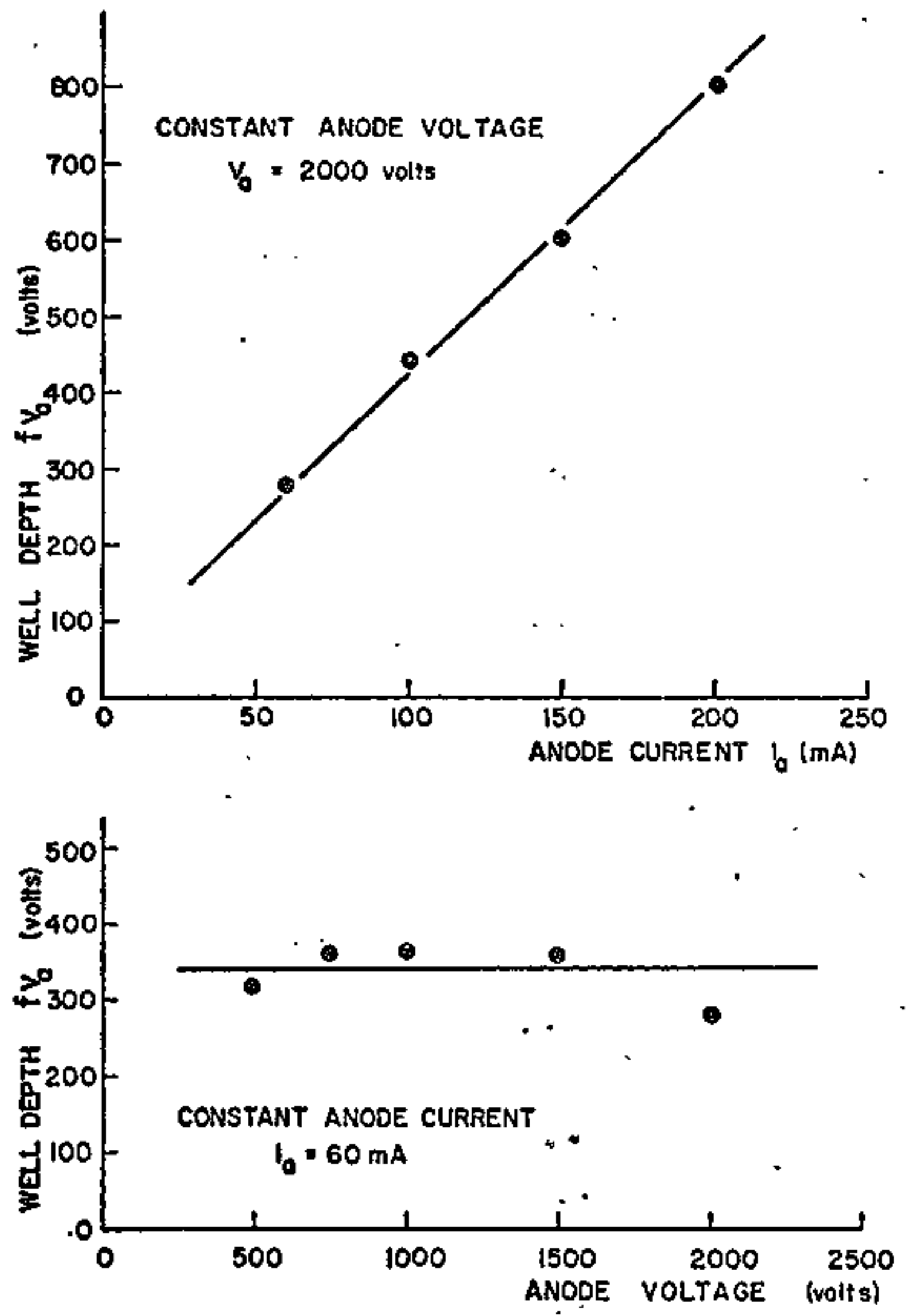

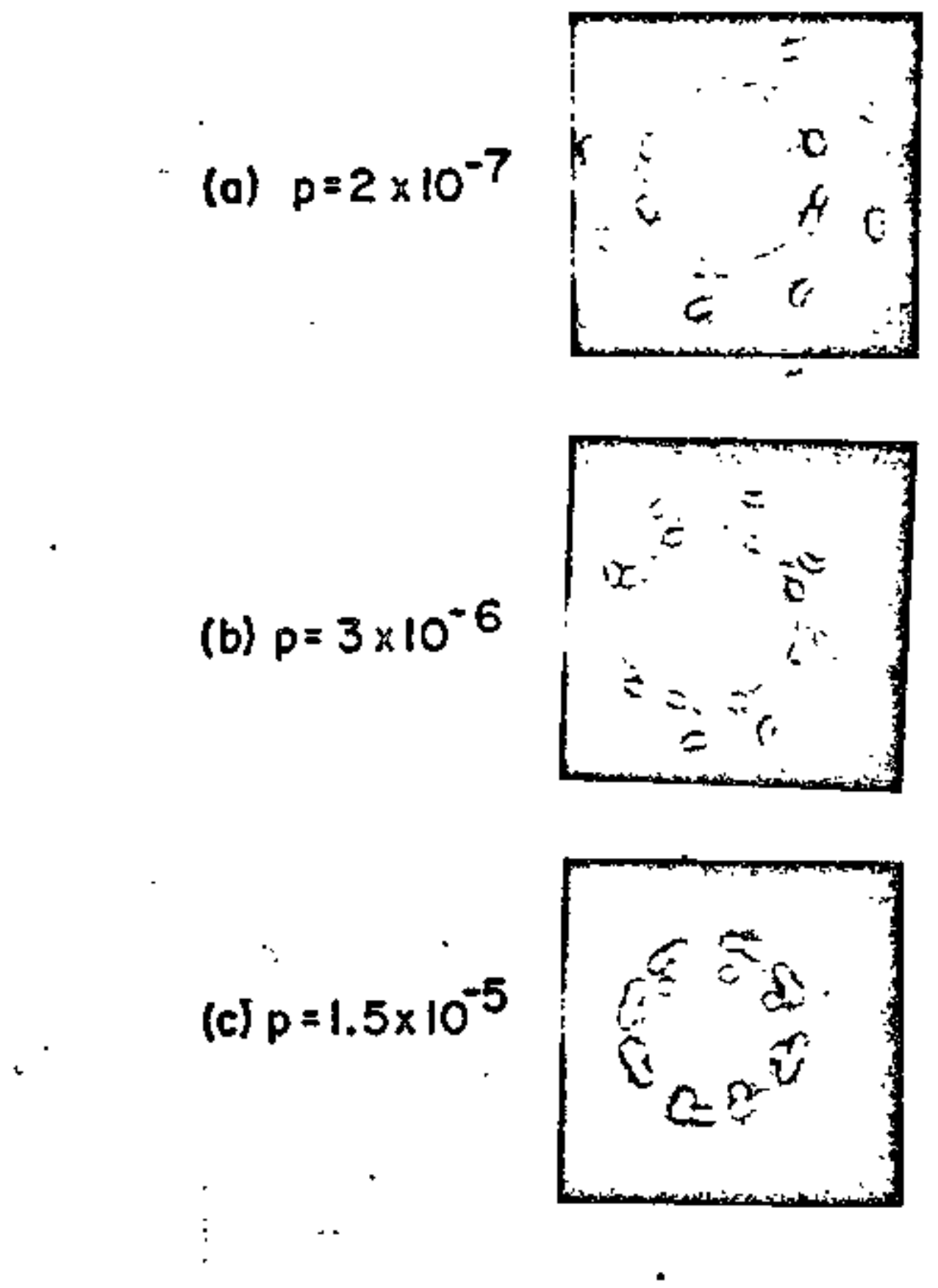
ELECTRON BEAM TRAJECTORIES
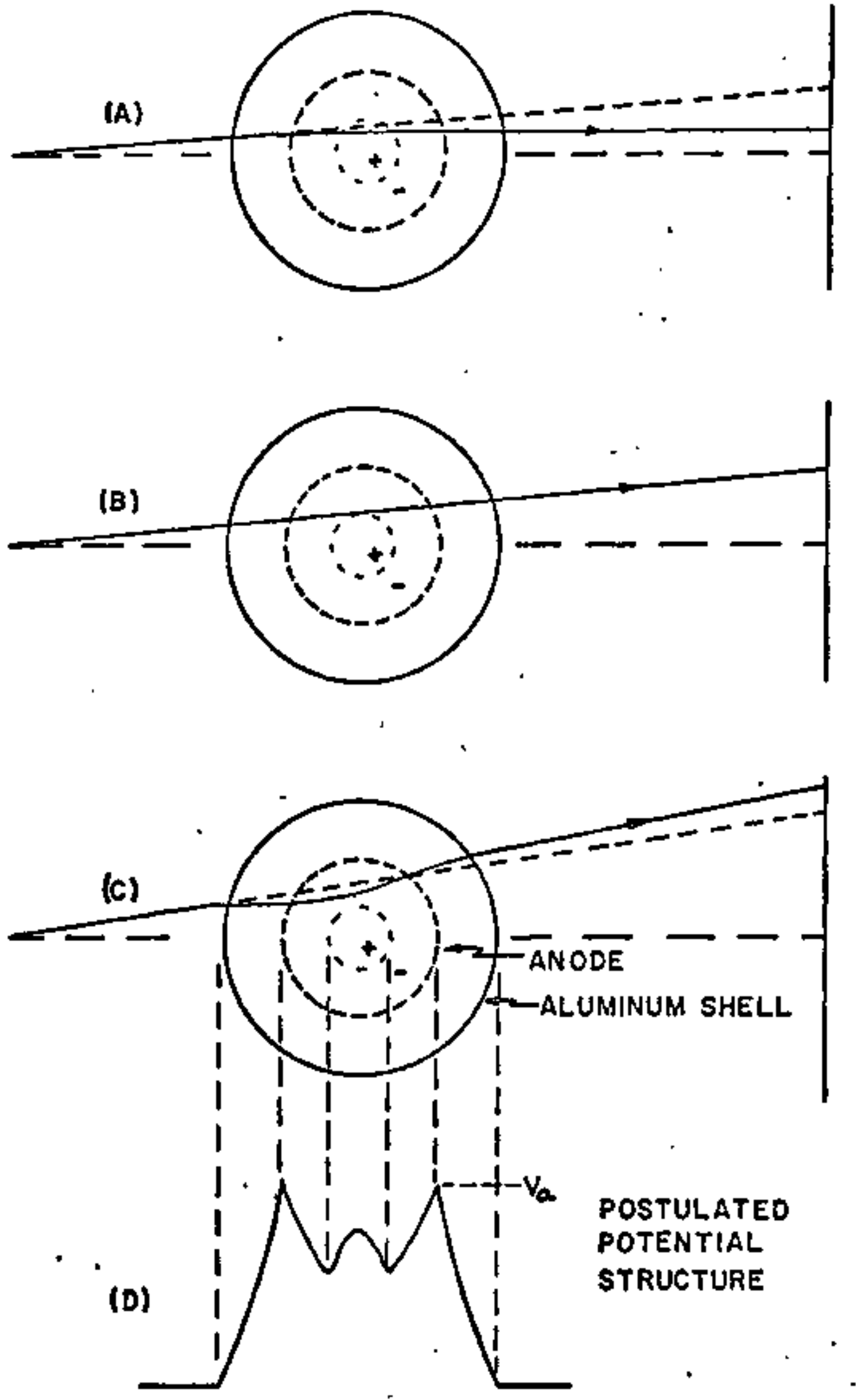

ELECTRON BEAM

PATTERNS

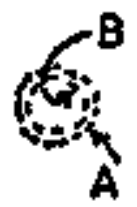

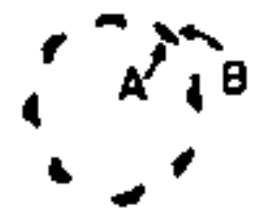

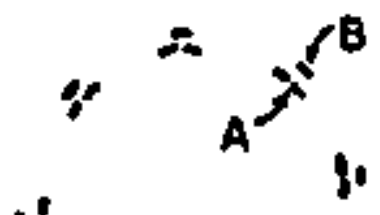

if

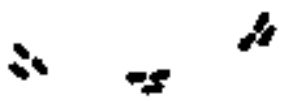




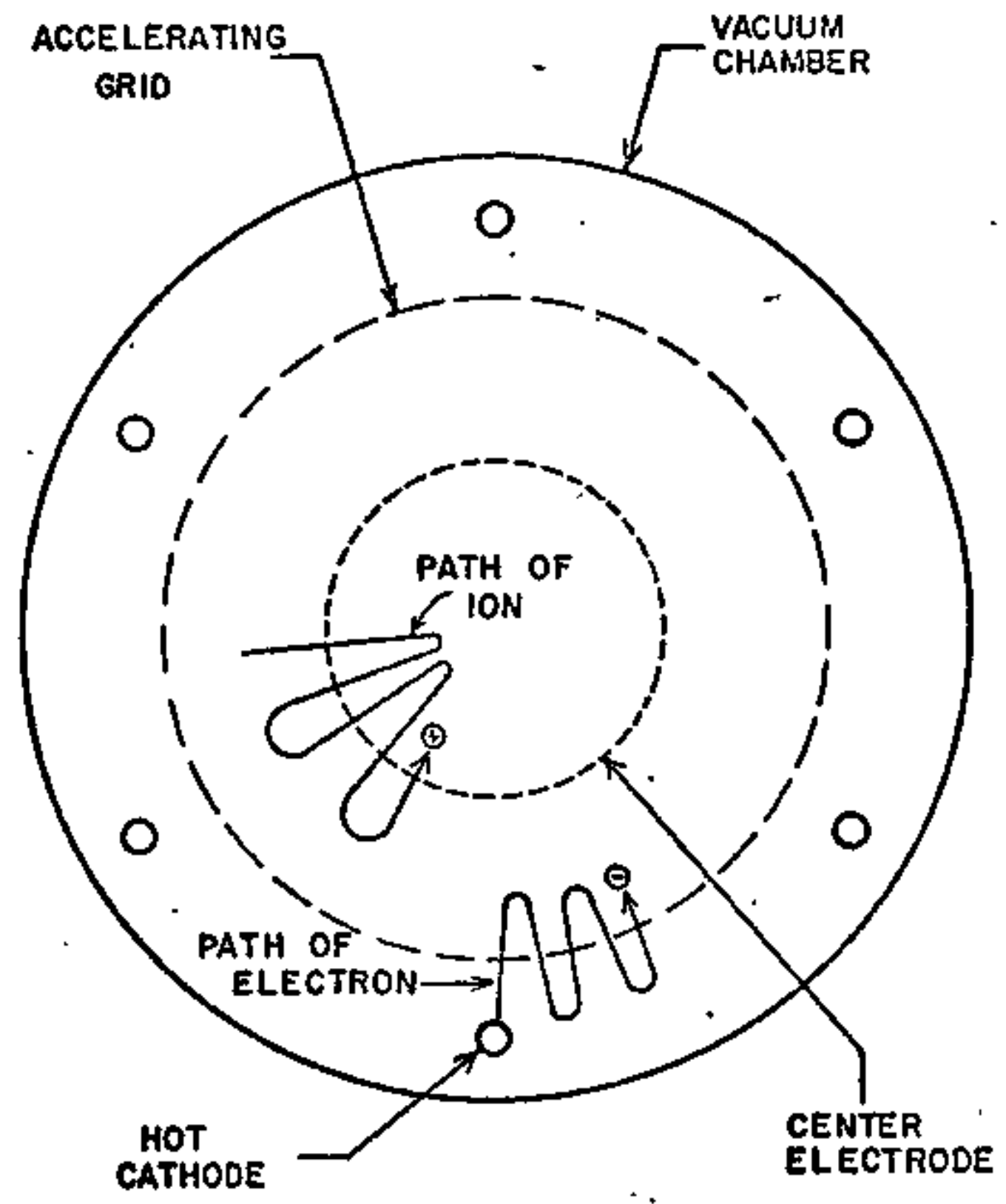

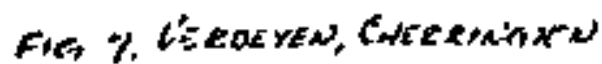




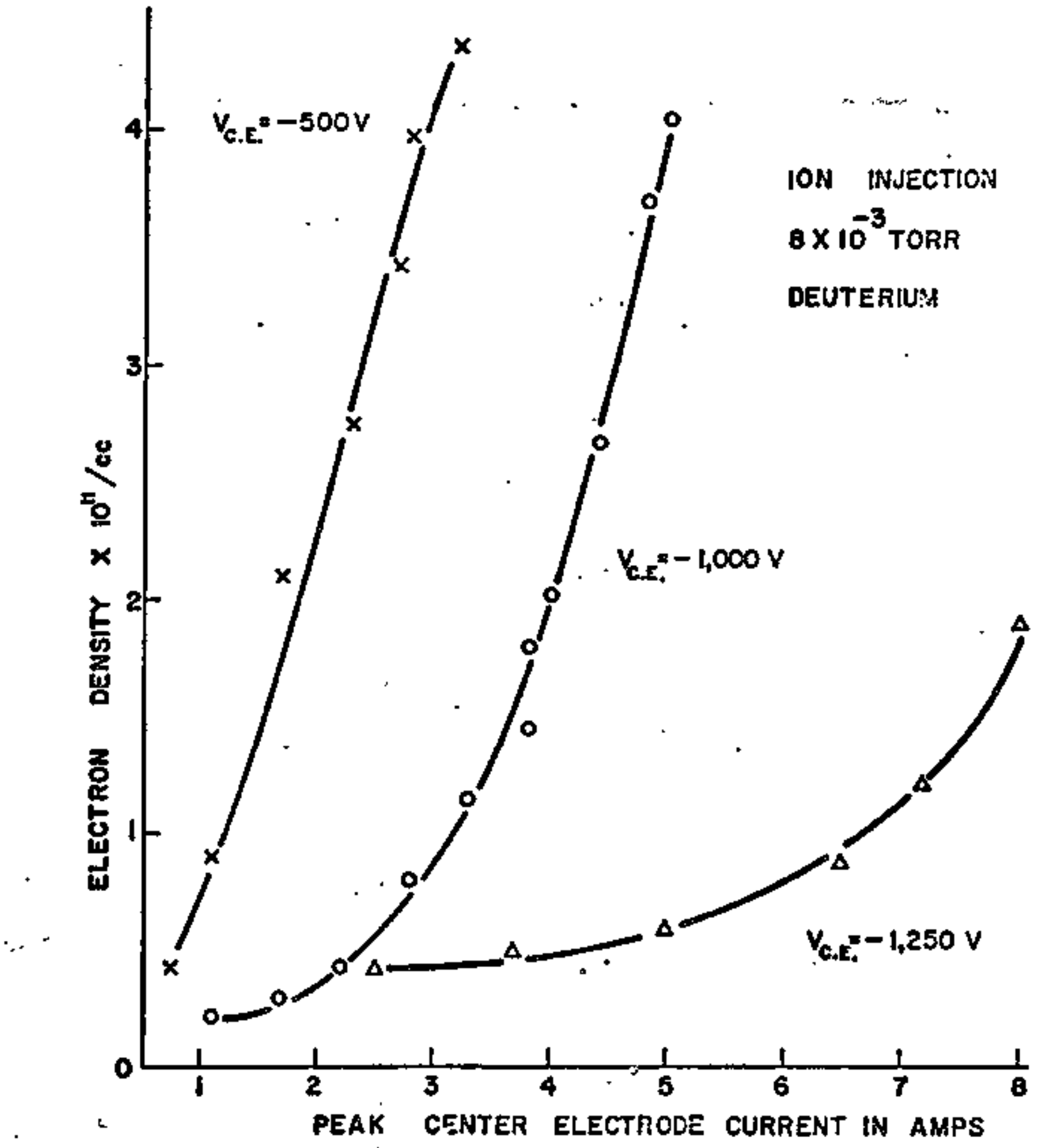




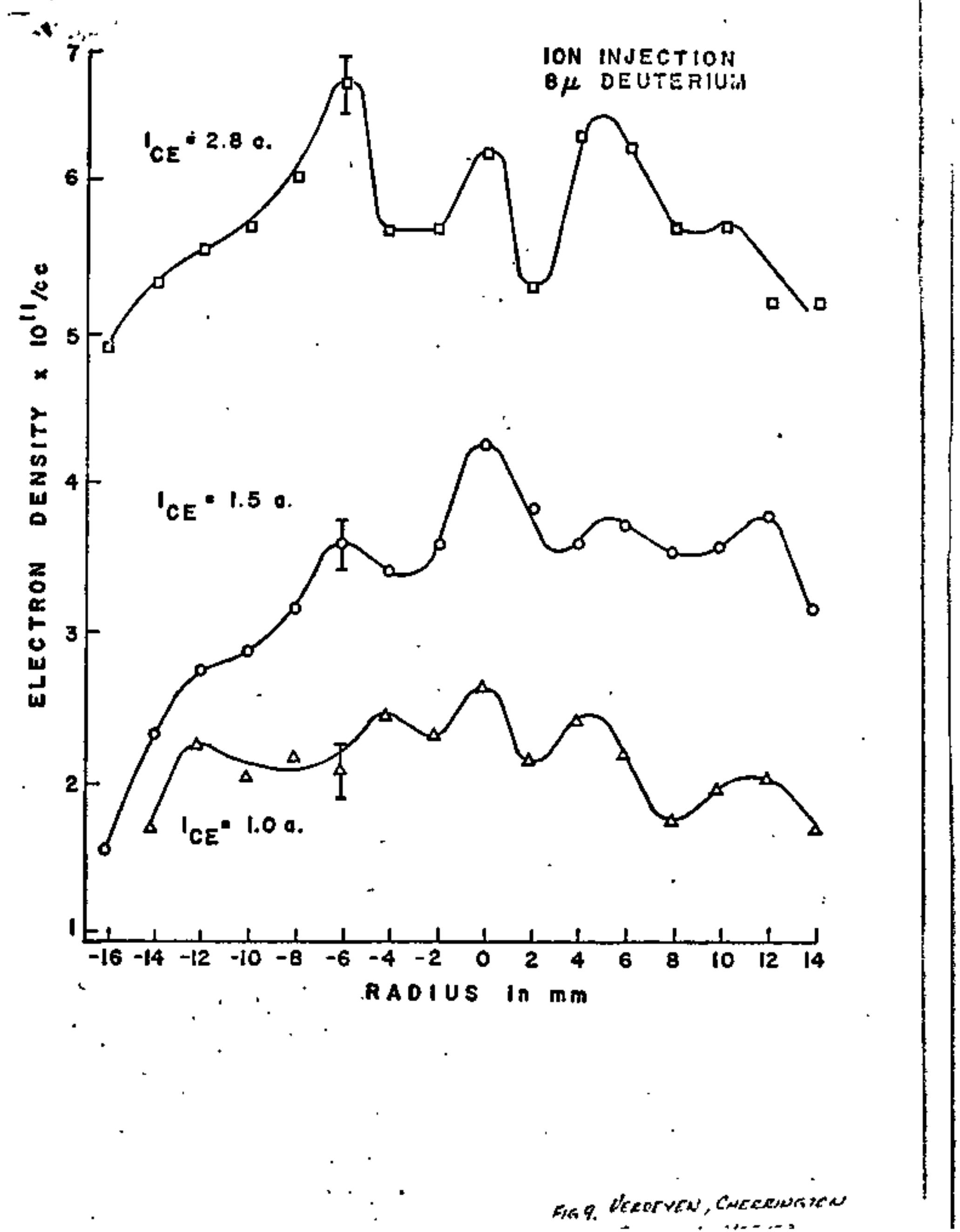




\section{RECENT DEVELOPAFNTS IN ELECTROSTATIC \\ CONFINELLNT - THEORETICAL}

\section{B.E. Cherrington, J.T. Verdeyen, and D.A. Swanson \\ Gaseous Electronics Laboratory, Department of Electrical Engineering, University of Illinois at Urbana-Champalgn, Urbana, IL 61801}

\section{Introduction}

The early interest in inertial-electrostatic plasma confinement as a possible technique for confining energetic lons for fuston purposes arose, In part, from the theoretical prediction, based on Poisson's equation, of the existence of altemating potentfal wells inside a spherical electrode into wh1ch were injected positive and negative charge species. 1 This suggested that sufficiently intense electrostatic fields could be generated near the center of such devices so that extremely energetic lons could be contalned, and fuston could posstbly result. Not bnly is that orfginal electrostatic confinement concept still of 1nterest, the Idea that infected charged beams can give rise to strong electrostatic flelds capable of trapping charged particles is also of broad Interest In magnetic or electromagnetic confinement gystems, particularly those employing neutral or Ion beam injection.

In order to trace the development of the theory, let us sumarize the approach. Folsson's equation along with the equations of conservation of energy and continutity of current are simultaneously olved for a spherfcal system where the electrode voltages and

* Thls work was supported by the U. S. Atonfc Energy

Comission under Contract $M T(11-1)-2323$. 
currents are consldered to be knarn. The solution for injection of : * single charged species dates back to the studies of tangmutr.

In his study, th was, assumed that the electrons started at a grounded cathode with no initial velocity and suffered no collisions in the system, therefore their radial velocity $v_{e}$ can be expressed in terms of the potential at. $r, v(r)$ as

$$
v=\sqrt{\frac{2 e v(\tau)}{m}}
$$

Since the system is spherically symetrlc, the current can be expressed as

$$
I_{e}=4 \pi T^{2} P_{e} v_{e}
$$

where $p_{e}$ is the electronic charge denstity' and Potsson's equation can then be expressed as

$$
\nabla^{2} V=\frac{1}{r^{2}} \frac{\partial}{\partial r} r^{2} \frac{\partial v}{\partial r}=\left[\frac{I}{4 \pi \varepsilon_{0} \sqrt{2 e / \pi}}\right] \frac{1}{r^{2} \sqrt{V(r)}}
$$

By nomalizing the radius to the electrode (anode) radius, $r_{a}$, and the potential to the anode potential $\mathrm{v}_{\mathrm{a}}$;

$$
\because \quad X=r / r_{a} \text { and } Y=V(r) / N_{a}
$$

and by defining 


$$
, k_{e}=\frac{I_{e}}{v_{e}^{3 / 2}} \cdot\left(\frac{m}{2 \mathrm{e}}\right)^{1 / 2} \frac{1}{4 \pi \varepsilon_{0}}
$$

which is proportional to the perveance. Poisson's equation can be expressed simply as

$$
\frac{1}{x^{2}} \frac{\partial}{\partial X} x^{2} \frac{\partial Y}{\partial X}=\frac{R}{x^{2}} y^{-1 / 2}
$$

Langmuir solved this equation under the condition of a space charge Haited current and found \& potential distribution as shown in PiB. 1. Obviously electron infection results in the formation of a virtual cathode under Langmulr's assumption. Unforcunately, Langmuir's theory predicts the exis tence of a virtual cathode no matter how stall the current. This is at variance with our experimental results ${ }^{3}$ as well as those of $\mathrm{H} 1 \mathrm{rsch} .{ }^{4}$ Beforie we return to the modification of the theory, let's consider the extension of Langwerf's theory to two charge spectes, as done by Hirsch. I

In the previous case, we considered that the electrons originated at zero veloctty from a grounded cathode outs1de the anode and vere accelerated through the permeable anode forming a virtual cathode within. Hirsch reversed this step and assumed that 1ons were produced at a grounded anode and accelerated through a perneable cathode held at a negative high voltage - $v_{0}$. The results of this malysis would be the same, except that a virtual anode would be formed Instead of a virtual cathode. Hirsch's addition was to allow the 
cathode to emit electrons (at zero Initial velocity) towards the center of the device.

In this case

$$
\frac{1}{2} M v_{i}^{2}=-\mathrm{v}(r)
$$

and

$$
\frac{1}{2} \text { in } v_{e}^{2}=e\left[v(r)+v_{0}\right]
$$

where $-v_{0}$ is the cathode potential.

Equation 6 then becomes

$$
\left.\frac{1}{x^{2}} \frac{a}{\partial X} X^{2} \frac{\partial Y}{\partial x}=\frac{x_{I}}{x^{2}}\left[Y^{-1 / 2}-\lambda_{1}(1-Y)^{-1 / 2}\right)\right]
$$

where

$$
\begin{aligned}
& \lambda_{1}=\frac{I_{e}}{I_{1}}\left(\frac{m}{M}\right)^{1 / 2} \\
& x_{1}=\frac{I_{1}}{v_{0}^{3 / 2}}\left(\frac{M}{2 e}\right)^{1 / 2} \frac{1}{4 \pi \varepsilon_{0}} \\
& Y=-v(r) / N_{0}
\end{aligned}
$$


and $x=r / r_{a}$ where $r_{a}$ is the radius of the vircual anode (zero potential) forred within the real cathode. The solution of equation 9. an example of with is shown in Fig. 2, shows the existence of alternating virtuel anodes and cathodes within the real cathode and the existence of very latge electrostatic fields near the center of the device.

How, obviausly, the solutions to these single particle as well as top particle tnfection equations can be expected to give highly 1dealized results. Our experiments bave shown that Langmuir's bolution is not realistic for electron infection only. We have also ohom experigentally that electrons and ions can form a wuleiple potential structure. Our nost recent theoretical woxk, therefore, has been to attempt more realistic solutions, to Polss on's equations for both single particle and duel particle injection to see if a reasonable cortelation to our experimental daca can. be found and to eee If a flrwer theoretical foundation for electrostatle confinement can be latd.

Single Species Injection with Spreads In Energy and Momentum

In ordex to develop a more realistic model for electron Injection only, we have included spreads in energy of the Injected particles as' well as spreads in their angular monentur. The technique use is the same as that used by Dolan' 5 ased on Lavrentyev's 6 
analysts of Polsson's equation with spreads in energy end angular motuenta.

Once again, we assume that electrons are injected into the Interfer of a permeable spherical anode held at a positive potential $v_{a}$ We no longer assume that the electrons have zeto total energy. We now express the total electron energy, -e $w_{e}$ as

$$
-w_{e}-\frac{1}{2} m v_{r}^{2}+\frac{1}{2} m v_{\phi}^{2}-e v(r)
$$

In this case, the electrons at the arode can have any chosen distrIbutions of total energy of from 0 to $e v_{a}$ corresponding to electron velocities at the anode of $\frac{2 \mathrm{e}}{\mathrm{u}}$ to zero respectively. We neglect collistons, so for any given particle, the total energy is conserved. We also define an angtular energy, e $S_{e}$, for each particle, which can be related to the angular morentum at the anode

$$
\text { - } s_{e}=\frac{z^{2}}{2 m r_{a}^{2}}-\frac{1}{2} m v_{\phi}^{2} \frac{r^{2}}{r_{a}^{2}}
$$

Once agatn, collisions are neglected so the angular energy is conBerved for any given particle and desired values of the angular energy distribution can be incorporated into the solution.

- Referring to Eq. (12), the radial veloctty

$$
v_{r}=\sqrt{\frac{2 e}{m}}\left[V(r)-W_{e}-s_{e} \frac{x_{A}^{2}}{r^{2}}\right]^{1 / 2}
$$

as compared to Eq. (1). 
The current consists of the motion of electrons with a distribution in $w_{e}$ and $s_{e}$

$$
I_{e}\left(S_{e}, w_{e}\right)=4 \pi r^{2} o_{e}\left(r, S_{e}, w_{e}\right) v_{r}\left(S_{e}, w_{e}\right)
$$

Sa that the charge dengity Involves a double integral over $s_{e}$ and i.

$$
p_{e}(r)=\int_{0}^{v(r)} \int_{e}^{\frac{r^{2}}{x_{a}^{2}}\left[v(r)-w_{e}\right]} d s_{e} \frac{I_{e}\left(s_{e}, w_{e}\right)}{4 \pi r^{2} \sqrt{\frac{2 e}{a}\left[v(r)-w_{e}-s_{e} \frac{r_{z}^{2}}{r^{2}}\right]^{1 / 2}}}
$$

Consider the ligits of integration on $s_{e^{*}}$ A particle with a given total and angular energy at the mode will proceed towards the center of the system only to the point where the radial velocity is zero

$$
0=\nabla(r)-w_{e}-s_{e} \frac{r_{a}^{2}}{r^{2}}
$$

So, for particles of a given total energy, the electrons that contribute to $p(r)$ have angular energies in the range

$$
\text { , } 0 \text { <e } s_{e}<\frac{e r^{2}}{2}\left[v(r)-w_{e}\right]
$$


Also, the total current is

$$
I=\int_{0}^{v} d w_{e} \int_{0}^{v^{-W} e} I_{e}\left(s_{e}, w_{e}\right) d s_{e}
$$

Using the save normalization as before

$$
\begin{aligned}
& X=r / r_{a} \\
& Y=V(r) / N_{a} \\
& Y_{e}=W_{e} / N_{a} \\
& Y_{\downarrow}=S_{e} / V_{a}
\end{aligned}
$$

We obtala

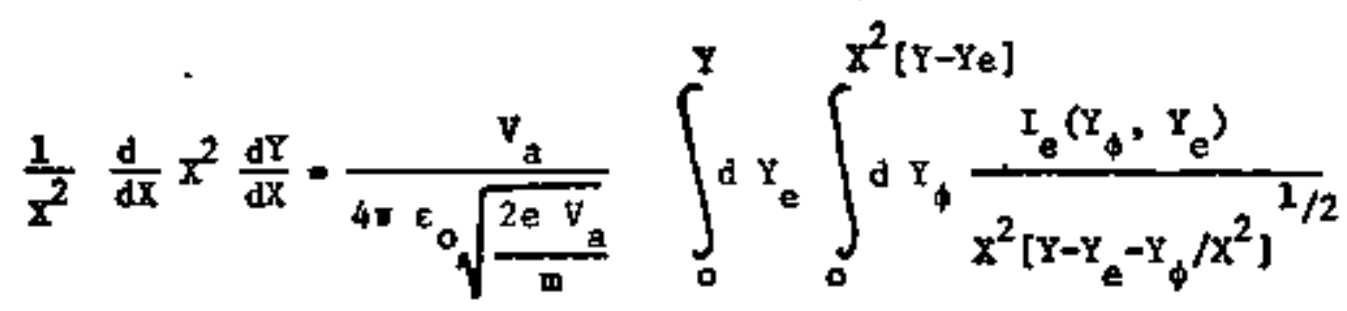

and $I-V_{a}^{2} \int_{0}^{1} d Y_{e} \int_{0}^{I-Y_{e}} d Y_{\phi} I_{e}\left(Y_{e}, Y_{\phi}\right)$

Equations (21) and (22) were evaluated for gquare and Boltzmann (Gausgian) distributions as shown in Fig. 3. The resuleg are quite atular, so we will discuss only the Gaussian distribution

$$
I_{e}\left(Y_{e}, Y_{\phi}\right)=A_{e}^{-Y_{e} / \sigma_{e}} e^{-Y_{\phi} / \sigma_{\phi}}
$$


In order to keep the volumes of the elements shown on Fig. 3 (circulating current) Independent of the anode voltages and distribution widths $\sigma_{\phi}$ and $\sigma_{e}$, the value of $A$ is taken to be

$$
A=\frac{I}{v_{a}^{2} \sigma_{\phi} \sigma_{e}}\left[1-e^{-1 / \sigma_{a}}-\left(\frac{\sigma_{\phi}}{\sigma_{\phi}-\sigma_{e}}\right)\left(e^{-1 / \sigma_{\phi}}-e^{-1 / \sigma_{e}}\right)\right]^{-1}(24)
$$

We also know that the clrculating current can be written in terms of the anode current

$$
I=I_{a}\left[\frac{2 n}{1-n^{2}}\right]
$$

where $n$ is the openness of the anode.

Equation (21) can therefore be rewititen as

$$
\frac{d}{d X} X^{2} \frac{d Y}{d X}=x_{e} \int_{0}^{Y} d Y_{e} \int_{0}^{X^{2}\left[Y_{-Y}\right]} d Y_{\phi} \frac{e^{-Y_{e} / Y_{e}} e^{-Y_{\phi} / \sigma_{\phi}}}{\left[Y-Y_{e}-Y_{\phi} / X^{2}\right]^{1 / 2}}
$$

where $K_{e}$, which is related to the perveance, Is

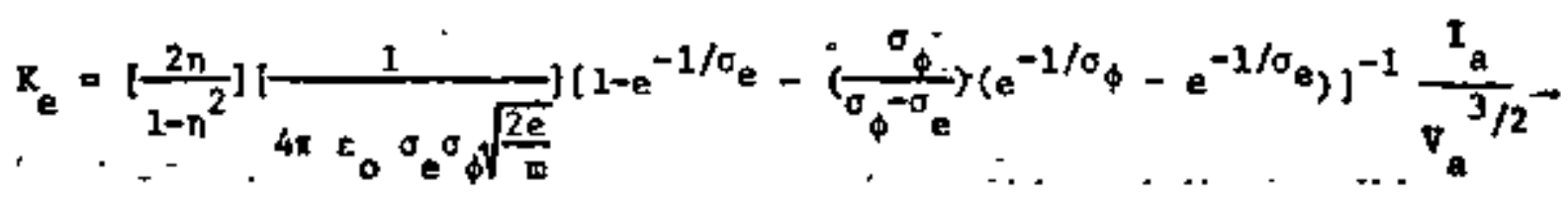

$$
\begin{aligned}
& :-\ldots \\
& -\because \quad-\quad-\ldots
\end{aligned}
$$


Equation (26) has been solved for the potent1al and charge distributions within the snode.

We have chosen $\pi=.9$ and we have used anode voltages and anode currents typlcal of those used in oux experiments with an anode of raditus $3.175 \mathrm{~cm}$.

Figure 4 shows the potential formed within the anode for $v_{a}=1000$ volts, $I_{a}=100 \mathrm{~mA}$ under the assumption of a narrow spresd In total energies $\left(\sigma_{e}=0.05\right)$ and a spread of angular energies from very wide $\left(\sigma_{\phi}=0.8\right)$ to narrow $\left(\sigma_{\phi}=0.05\right)$. The results sre very different from the Langmutr solution (Fig. 1). This figure shows that for narrow spreads in energy and angular tomentum we approach the Langmuir solution, as expected, but that as the angular epread increases the depth of the well decteases considerably. We also see that relatively small amounts of angular momentum, which could be eastly generated by the wire structure of the anode, would result in a potential weIl with an approximately parabolic shape. This parabolic shape is in excellent agreement with our experimental results. We have seen the sensitivity of the depth of the well on angular momentum. Figure $S$ shows the dependence of the well shape on total energy spread for a fixed narrow spread (0.05) in angular mowentum. AB can be seen, spreads in total energy have relatively little effect on the well shape or depth. Angular momentum appears to be the Important factor. 
In order to facilltate comparison to our experimental results, Fig. 6 shows the potential variation for a fixed spread in total energy and angular energy $\sigma_{e}=\sigma_{\phi}=0.05$ and for a fixed anode voltage, $v_{a}=1000$ volts, but with a varlable anode current. Each curve is labeled with four numbers. The first is the fractionsI well depth $f$, the second is the anode current (mA), the third is the snode voltage (voits) and the fourth is $\mathrm{K}_{\mathrm{e}}$ wh1ch is related to the perveance. As can be seen, the well depth increases with 1ncreasing current for a given anode voltage. Figure 7 shows a plot of $f$, the fractional well depth, vs anode current for a fixed anode voltage of 2000 volts. Also show are the experimental data points that we have obtained for the same conditions. The agreement is qufte good and shows an essentialiy linear increase in well depth wth Increasing current.

Figure 8 shows a plot which is similar to Fig. 6 except that the anode current is held constant at $100 \mathrm{~mA}$ and the anode voltage is varfed. Figure 9 shows a plot of the absolute welt depth, $f \mathrm{v}_{\mathrm{a}}$, vs anóde voltage for an anode current of $60 \mathrm{~mA}$ along wth the experimental data points for the same conditions. Again, the agreement is quite good and shows that the absolute well depth 1a relatively Independent of the anode voltage over quite a large range ss $1 \mathrm{hng}$ as the anode voltage is held fixed.

The excellent agreement becween the theory and expertment for electron infection only indicates that this theoretical approsch 10 valid. The theory also shows that the spread in angular energy 
Is the critical factor in deternining the depth of the electrostatic vells formed. If square distribucion functions are used, essentially ointlar results are obtained as we found in our previous work and which have also been found by Imel, ${ }^{7}$ so the form of the angular energy distributions are not critical, only the fact that chey exist.

Two Species Injection with Spreads

In Energy and Angular Momentum

The logical extension of the single spectes study is to two species injection to see 1 the multiple potential welis are still pred1cted, Certainly our experiments suggest that they do exist, A theoretical confirmation would be most useful in helping us to deternine under what conditions the multiple potential well exists. Unfortunately, our experimental conditions cannot be easily represented by such a simple model. Colifsions are obviousty toportant in our experibent as a source of positive tous. Collisions were neglected In the theory. Possibly, however, modiflcations to the total eneigy and angutar energy spreads could compensate.

Inftlal studies In this area have alreaty been performed by Dolan. The approach is identical to that for single particle Infection, anly both electrons and lons are considered and both are considered to have spreads in total enerby and angular energy. Dolan solved for the potencial within the anode for an approximstely Gaussian shaped energy distribution (rather than step function) of lons and electrons. Unfortunately, he found no multiple potential 
well structure for the conditions of falrly wide total energy and engular energy distributions. The range of variables he considered was small, however, so we have continued to solve the equations wth two charged spectes for a wide range of variables.

As a model of our experimentai systen, we have kept the electron spreads in total and angular energies relatively small and close to those values that seen to match our experimental electron Injection only conditions. We expect that the ions are produced by lonizing collisions with the background gas within the anode, so we would expect the electrons to have a wide spread in total energies (corresponding to being born anywhere within the anode). For our Initial analysis, however, we have kept the spreads In total energy and angular energy relatively small. Inder these conditions, we have found potential soluttons whtch show a multiple potential structure. This is shown in Fig. 30 . In fact, such bolutions do appear to exist for a range of variables, although ar the moment a strictly liaited range. It should be pointed out, however, that there is' still some question as to whether or not these solutions are mique. In some cases several solution, IncludIng those which axe similar to Dolan's and show no nultiple potent1al structure, are posstble for the same conditions for which - colution showing a multiple potential well gtructure has been found.

our present work is concemed with further examination of the conditions for and the uniqueness of the multiple potential 
well solutions for two species injection in spherical geometry. Our Initial results, although far from definitive, do indicate that there is some primise of using the present theoretical madel to understand and predict multiple potential well formation in electrostatic confinement devices.

\section{Conclusions}

The solution of Poisson's equation in spherical coordinates for electron injection with spreads in total energy and in angular energy provides a realistic theoretical model for the potential within a spherical device for single species injection. The agreement between this theory and experimental results on ofmilar devices Is excellent. The essential factor in obtaining good agreement is the Inclusion of the angular motion of the injected particles. Preliminary theoretical results for two species injection Indicate. that this theoretical approach may also be able to be used to provide a model of the toultiple potential well structure observed in experimental devices for electron infection tnto a low pressure gas background. 


\section{References}

1. Hirsch, R. I. J. App1. Phys. 38: 4522 (1967).

2. Langmtiir, I., K, R. Blodgett. Phys, Rev, 24: 49 (1924).

3. Swans on, D. A., B. E. Cherrington, J. T. Verdeyen. Phys. Fluids 16: $1939(1973)$.

4. H1rsch. R. I. Phys. Fluids I3: 2486 (1969).

5. Dolan, T, J., J, T. Verdeyen, B. E. Cherrington, D. J. Meeker. J. App1. Phys. 43: 1950 (1972).

6. Lavrentyev, 0. A. Magnitnye Lousshki AEC report No. AEC-tr-7002, 1970.

7. Ime1, G. M. S. Thesis, Pennsylvania State University (1973). 


\section{Figute Captions}

F1g. 1. Normalized potential vs. normalized radius within the anode for monoenergetic electron injection with no angutar motion.

81g. 2. Nocmallzed potential vs, Iadius for monoenergetic electron and ion injection with no angtrlar momentum.

Fig. 3. Assumed step function and Gausstan distributions of the electron current.

Fì. 4. Normalized potential vs, normalized radius within the anode. The total energy spread is held constant and the angular energy spread is varied.

Fig. S. Normalized potential vs. normalized radius within the anode. The angular energy spread is held constant and the total energy is varied.

Fig. 6. Normalized potential vs, nomalized radius withta the anode for a constant voltage and varying curcent:

Fig. 7. Fractional well depth $f$, vs, anode current for $V_{a}=2000$

- Volts. Experimental and theoretical values.

Ffg. B. Normalized potential vs, normalized radius within the anode for a constant current and varying voltage.

$\mathbf{F I}$. 9. Absolute we1l depth, $f \nabla_{a}$, $\nabla s$, anode voltage for $I_{a}=60 \mathrm{~mA}$. Experimental and theoretical values.

F1g. 10. Multiple potential well structure for both electron and ton 1njection. A square distribution of energles has been used. (See FiB. 3). 


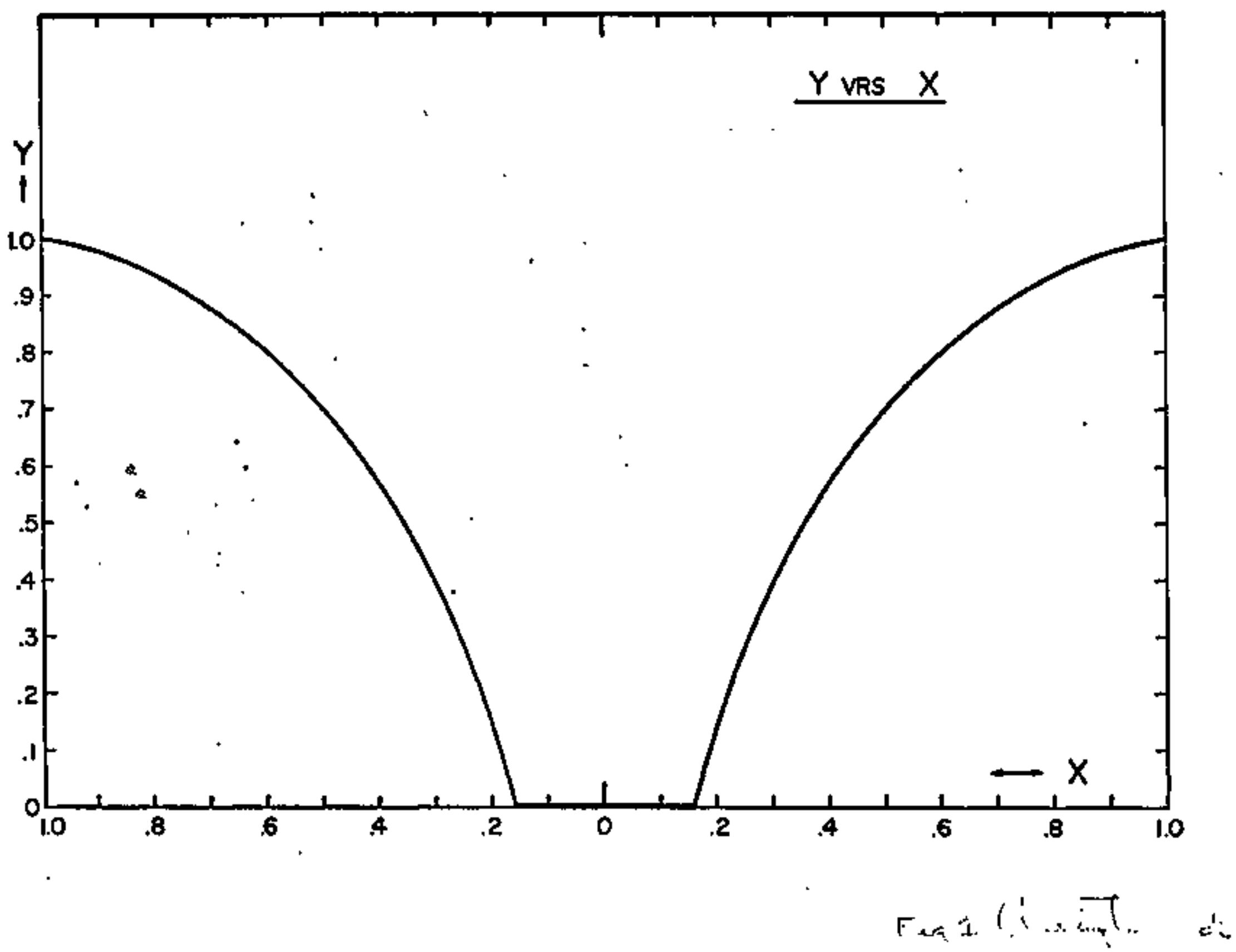



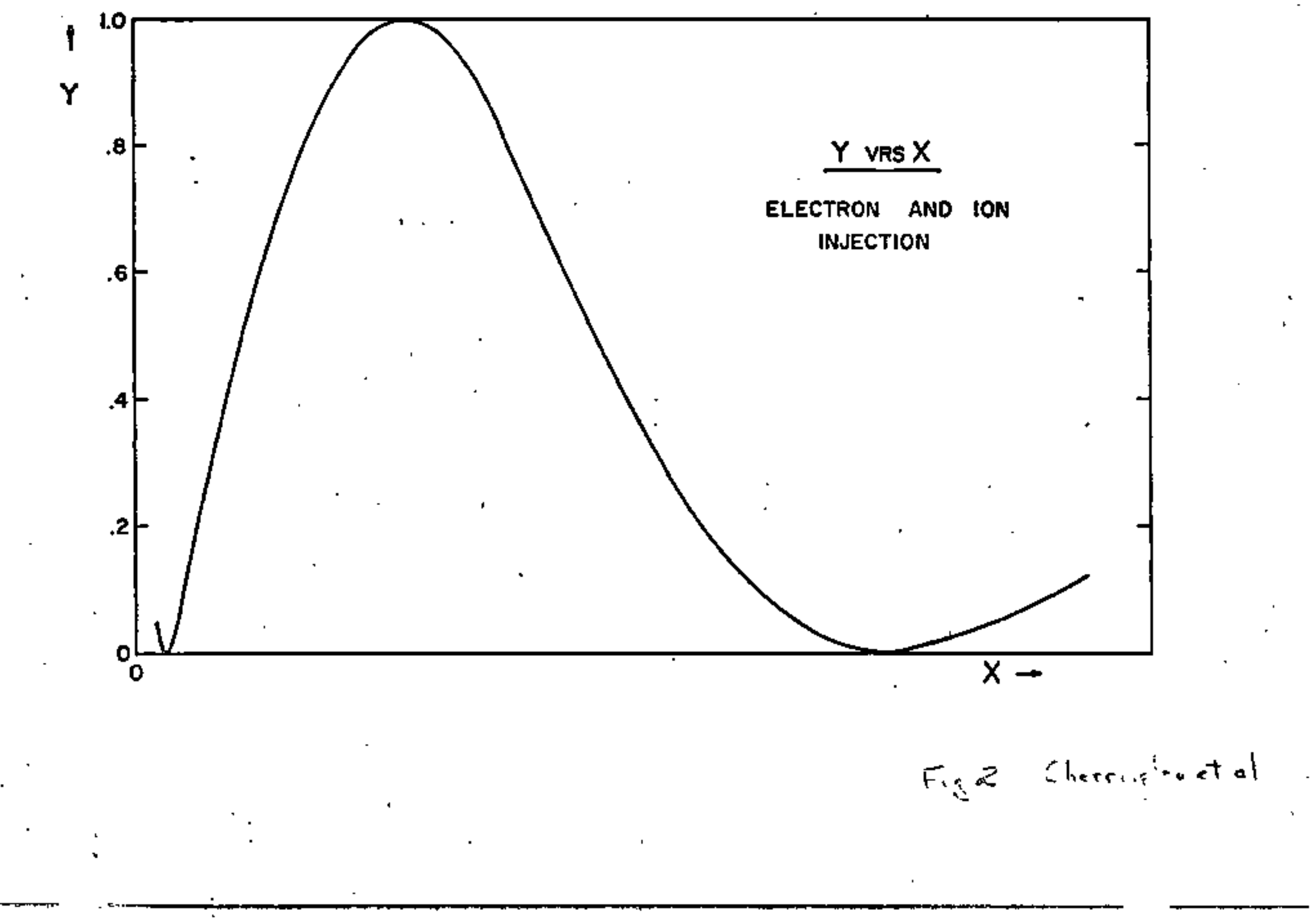


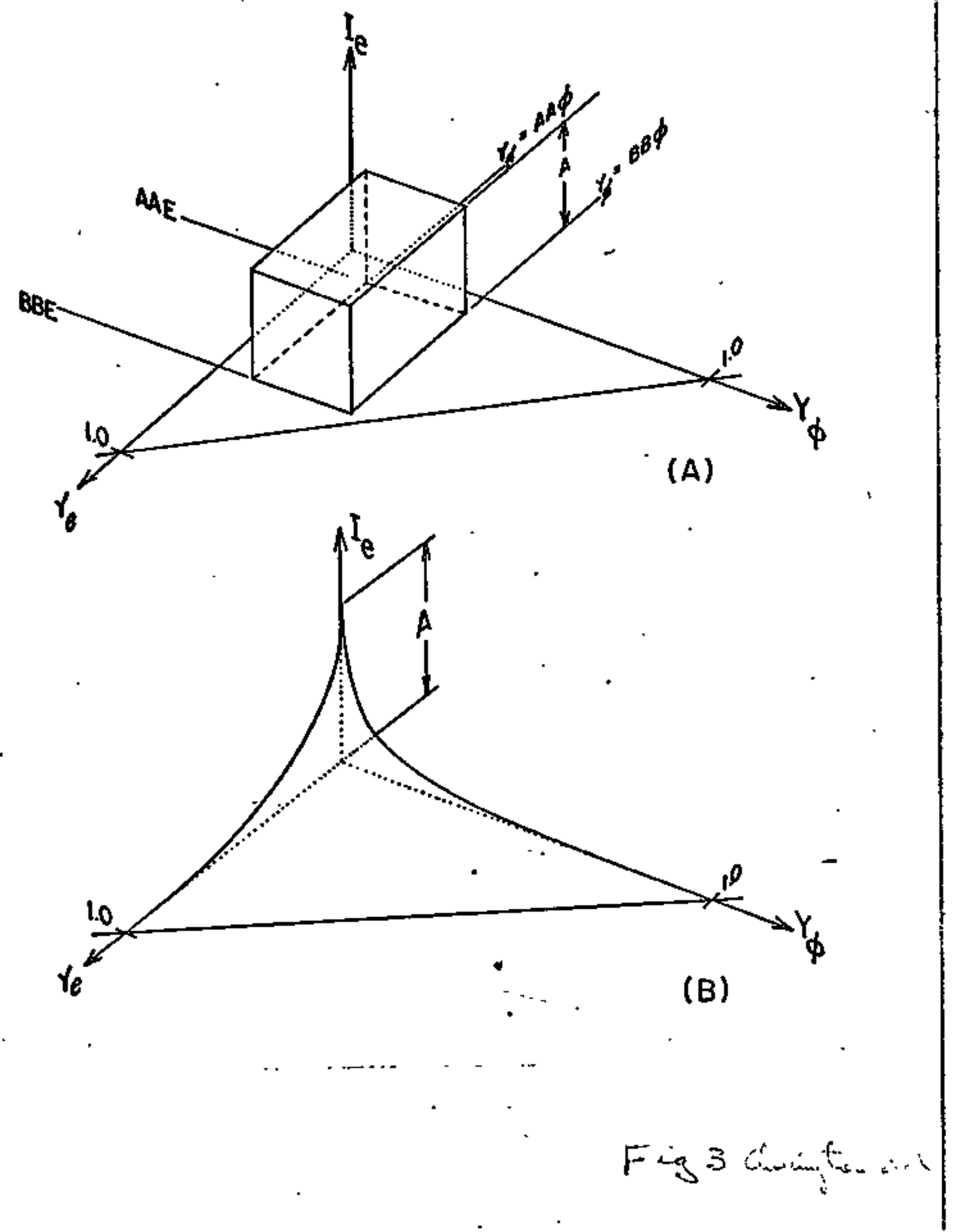




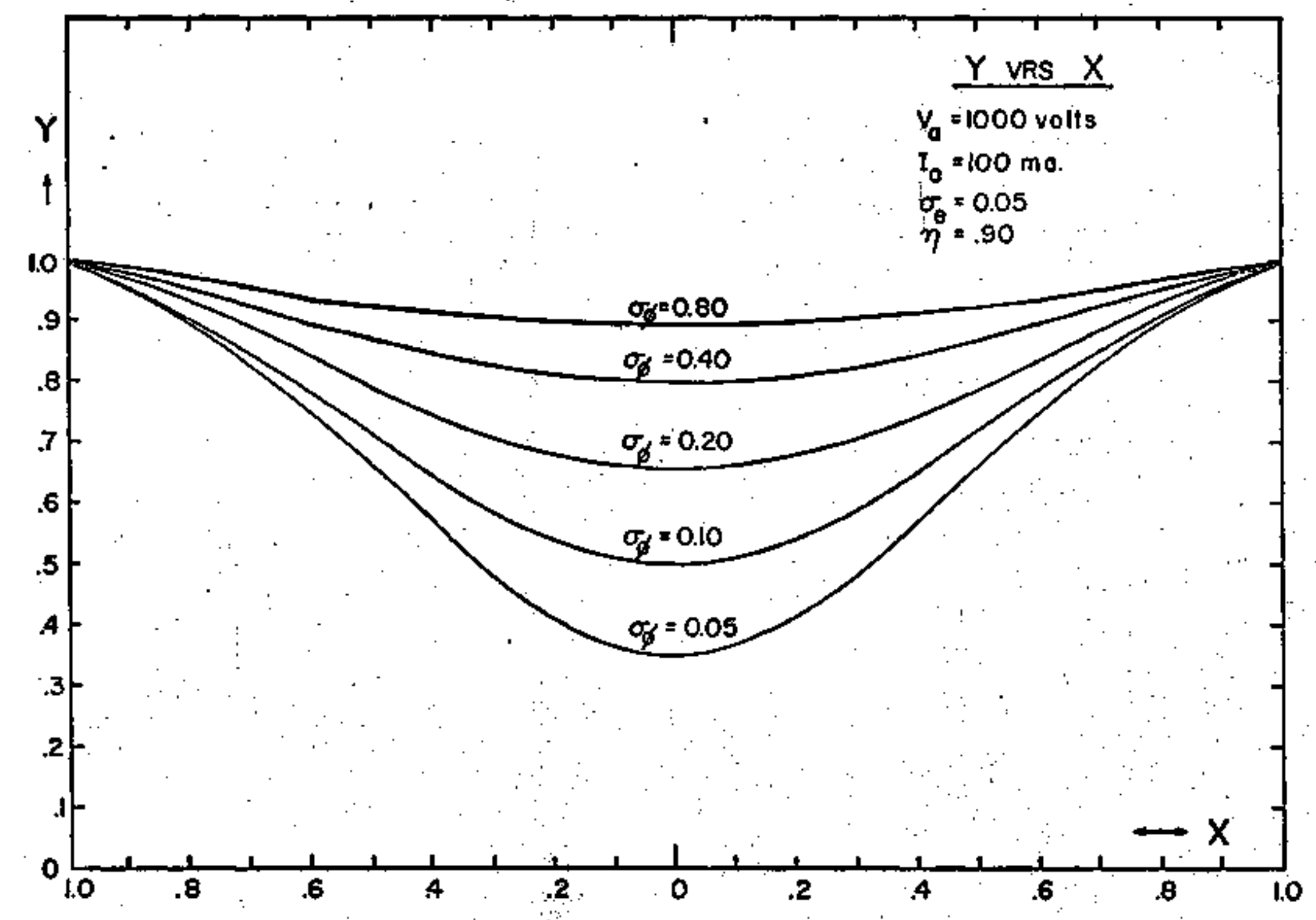

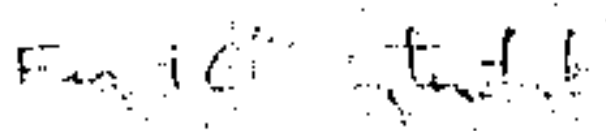




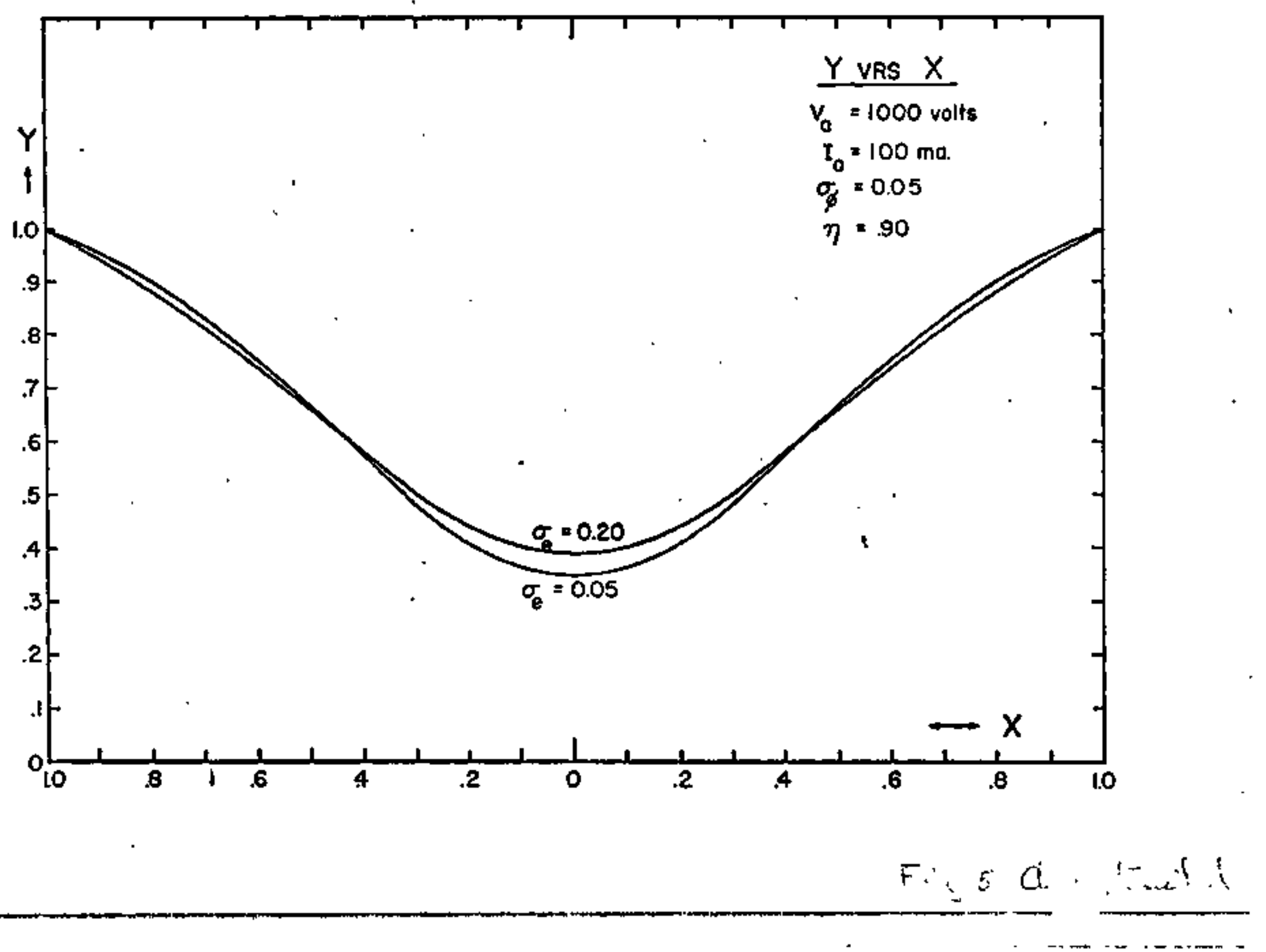




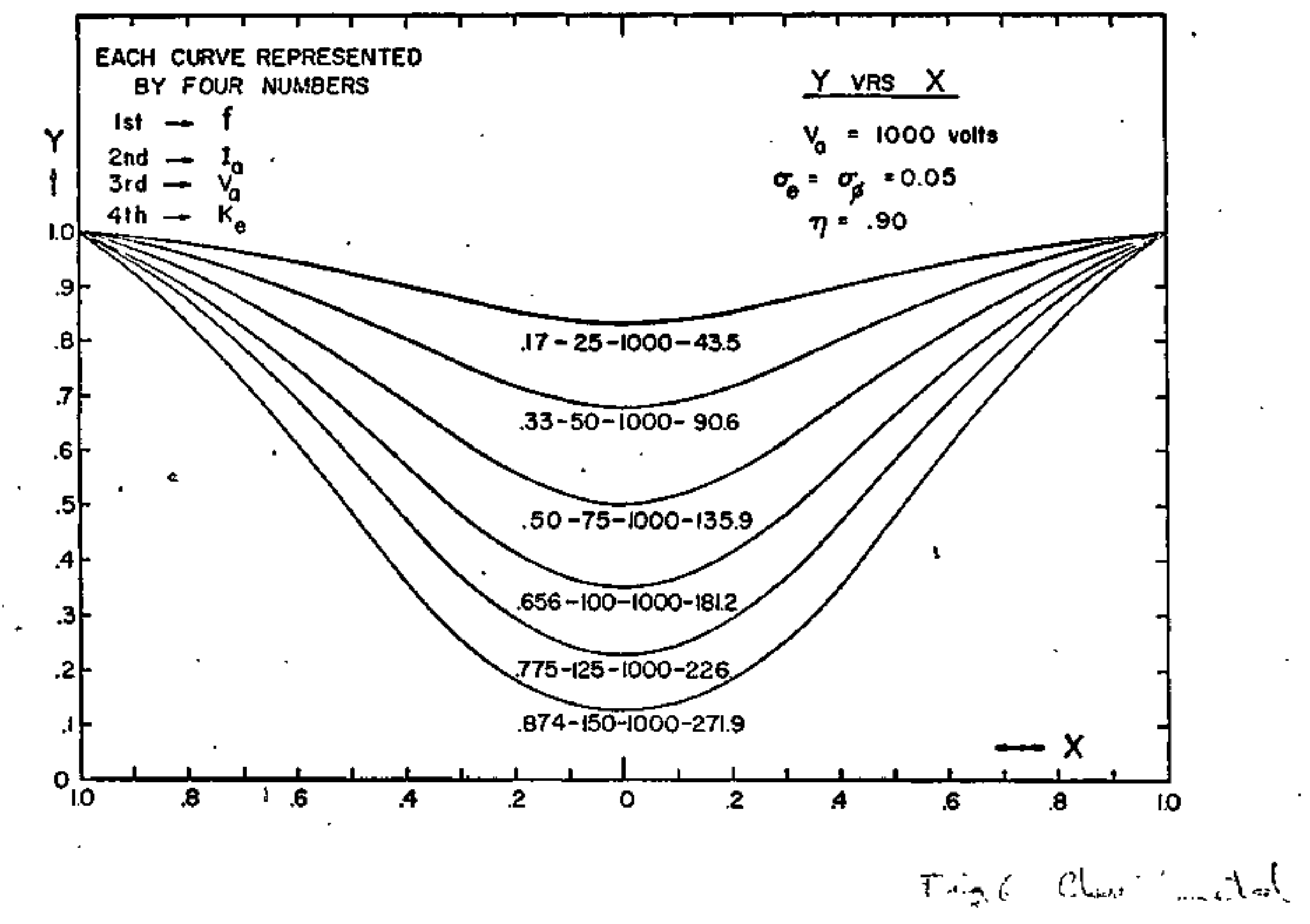




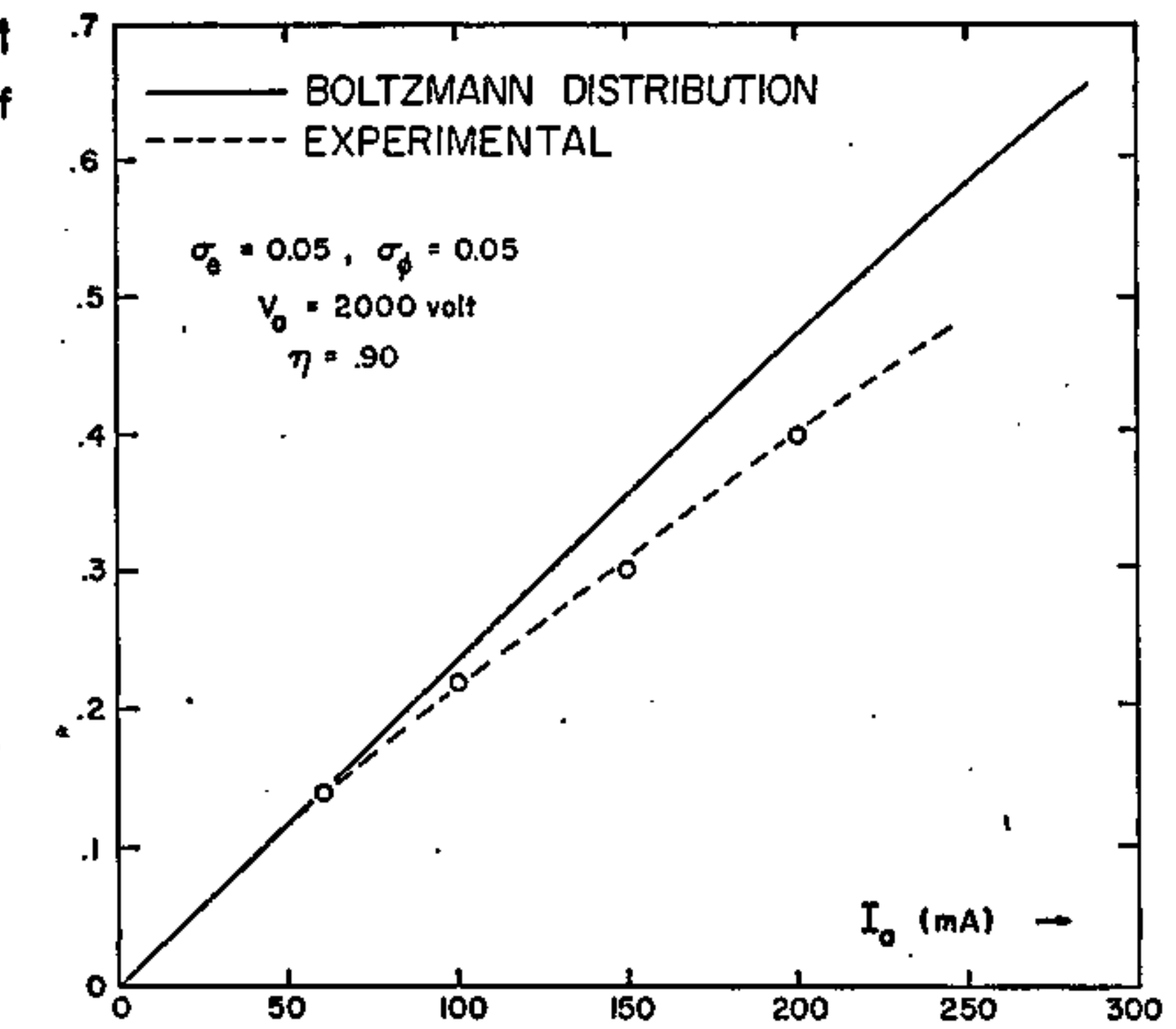

1

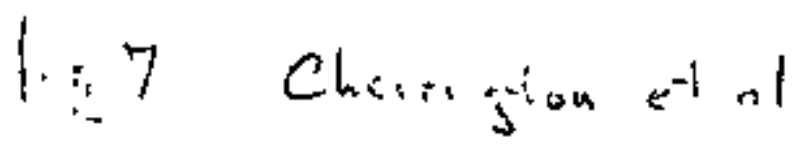




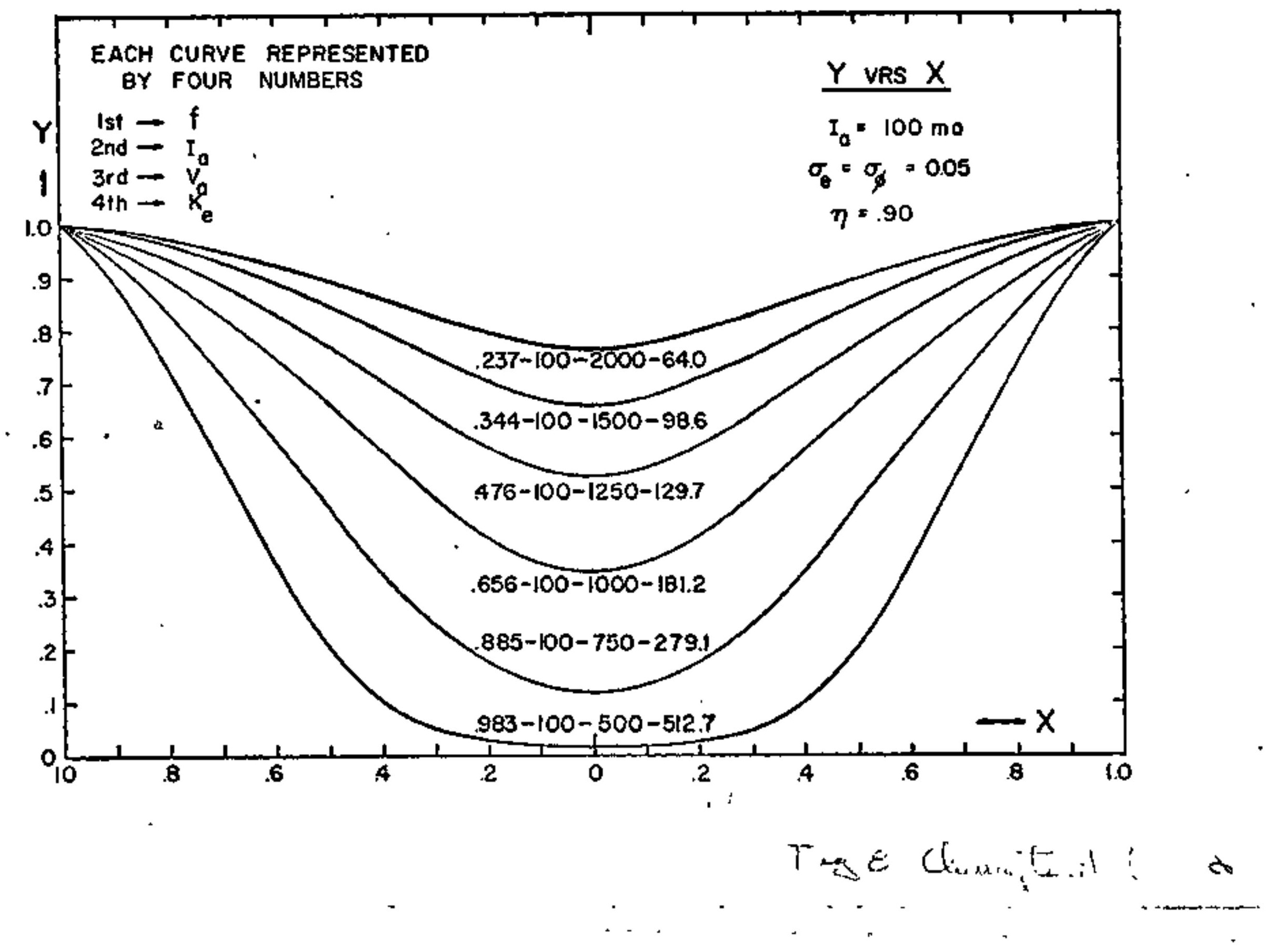




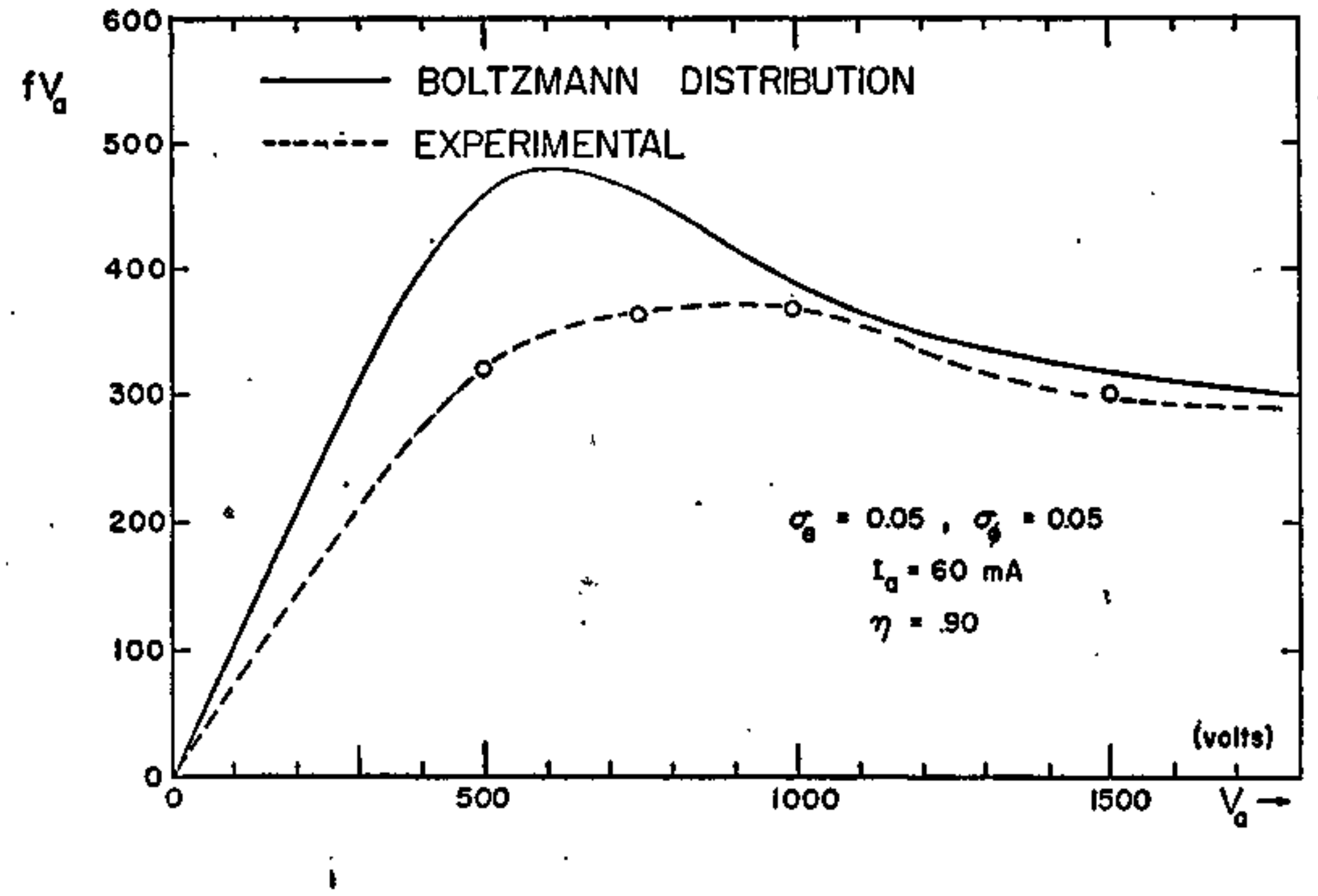

righa clandinetal 


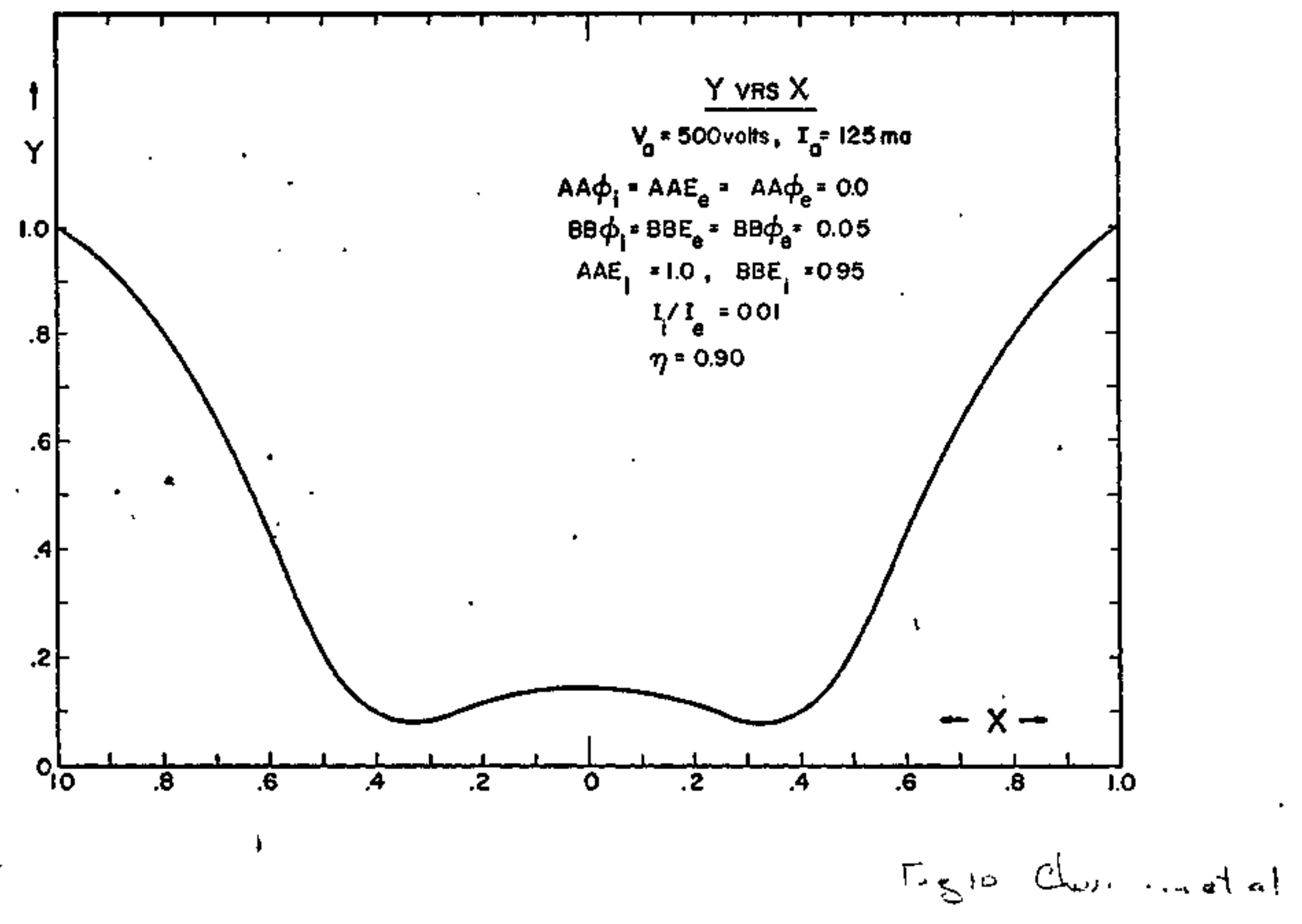

